\title{
Selective Catalysis with Peptide Dendrimers
}

Celine Douat-Casassus, Tamis Darbre and Jean-Louis Reymond*

Department of Chemistry and Biochemistry, University of Bern, Freiestrasse 3, 3012 Bern, Switzerland, FAX +41316318057

e-mail: reymond@ioc.unibe.ch 
Analytical HPLC profiles and Mass spectra (ESI MS) data for the monomeric and dimeric peptide dendrimers

Analytical HPLC columns: Chromolith Performance RP-18e , $0.46 \times 10 \mathrm{~cm}$, flow $3 \mathrm{~mL} . \mathrm{min}^{-1}$;

detection by UV at $234 \mathrm{~nm}$, solvent systems: $\mathrm{A}=0.1 \%$ TFA in $\mathrm{H}_{2} \mathrm{O} ; \mathrm{B}=40 \% \mathrm{H}_{2} \mathrm{O} / 60 \% \mathrm{CH}_{3} \mathrm{CN}_{\text {, }}$ $0.1 \%$ TFA.

Standard HPLC conditions: $100 \%$ A to $50 \%$ A in 10 min, or conditions indicated. 


\section{Dendrimer A}

Starting with $100 \mathrm{mg}$ of Rink amide resin $(0.61 \mathrm{mmol} / \mathrm{g})$, the sequence $\left((\mathrm{Ac}-\mathrm{Ser})_{2} \text {-B-Asp }\right)_{2}$-B-Cys-His$\mathrm{NH}_{2}$ was obtained as colorless foamy solid after preparative HPLC purification $(8.7 \mathrm{mg}, 10 \%)$. RPHPLC: $t_{\mathrm{R}}=5.95 \mathrm{MS}(\mathrm{ES}+)$ : calc. for $\mathrm{C}_{58} \mathrm{H}_{71} \mathrm{~N}_{17} \mathrm{O}_{23} \mathrm{~S}: 1405.75$, found: 1405.46 .
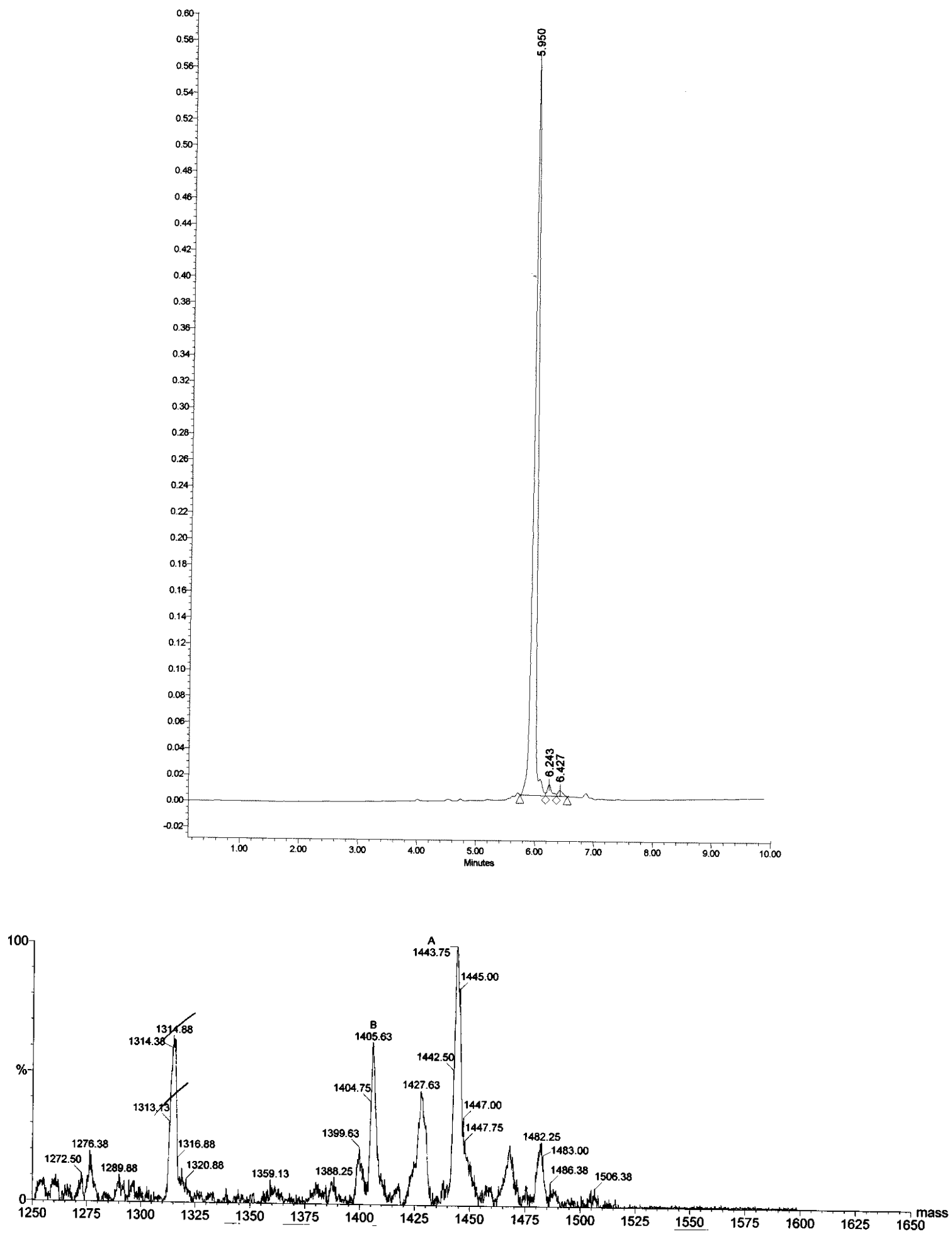


\section{Dendrimer B}

Starting with $100 \mathrm{mg}$ of Rink amide resin $(0.61 \mathrm{mmol} / \mathrm{g})$, the sequence ((Ac-Ser $)_{2}$-B-His $)_{2}$-B-Cys-Asp$\mathrm{NH}_{2}$ was obtained as colorless foamy solid after preparative HPLC purification $(10.7 \mathrm{mg}, 12 \%)$. RPHPLC: $t_{\mathrm{R}}=6.09 \mathrm{MS}(\mathrm{ES}+)$ : calc. for $\mathrm{C}_{60} \mathrm{H}_{72} \mathrm{~N}_{18} \mathrm{O}_{22} \mathrm{~S}: 1427.88$, found: 1428.48 .
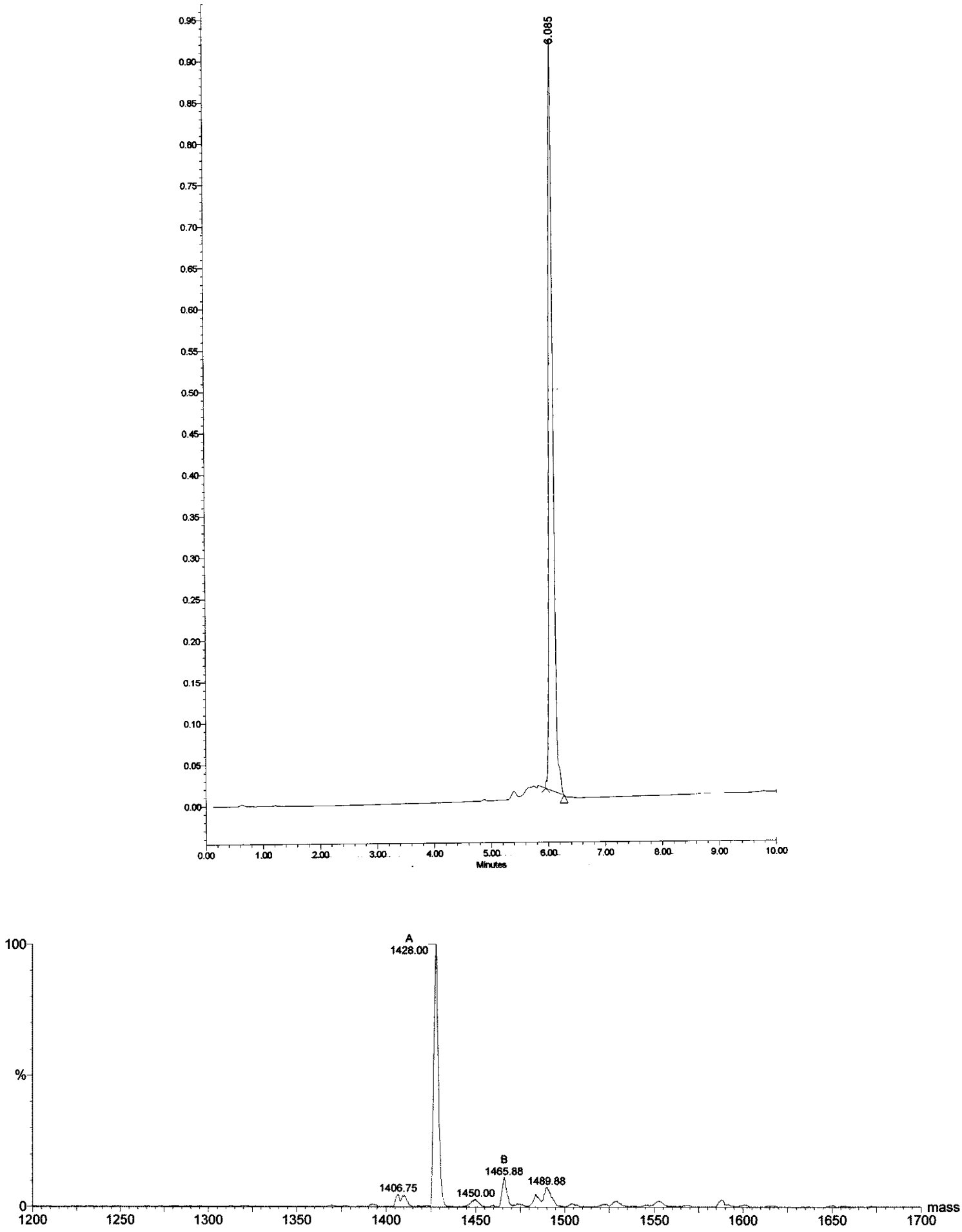


\section{Dendrimer C}

Starting with $100 \mathrm{mg}$ of Rink amide resin $(0.61 \mathrm{mmol} / \mathrm{g})$, the sequence ((Ac-Asp $)_{2}$-B-Ser $)_{2}$-B-Cys-His$\mathrm{NH}_{2}$ was obtained as colorless foamy solid after preparative HPLC purification (17.0 mg, 19\%). RPHPLC: $t_{\mathrm{R}}=5.84 \mathrm{MS}(\mathrm{ES}+)$ : calc. for $\mathrm{C}_{60} \mathrm{H}_{71} \mathrm{~N}_{17} \mathrm{O}_{25} \mathrm{~S}: 1461.45$, found: 1461.63 .
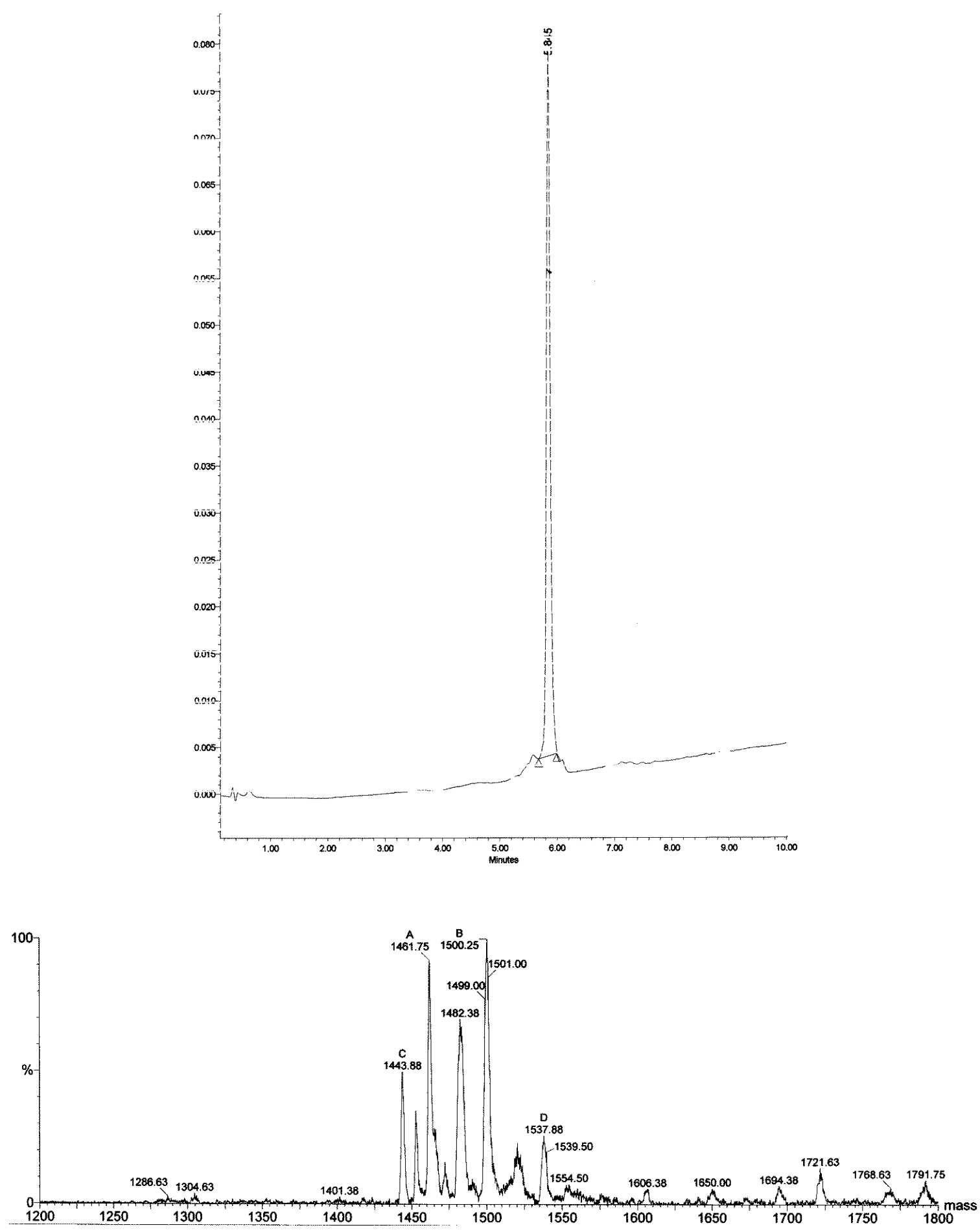


\section{Dendrimer D}

Starting with $150 \mathrm{mg}$ of Rink amide resin $(0.61 \mathrm{mmol} / \mathrm{g})$, the sequence $\left((\mathrm{Ac}-\mathrm{Asp})_{2} \text {-B-His }\right)_{2}$-B-Cys-Ser$\mathrm{NH}_{2}$ was obtained as colorless foamy solid after preparative HPLC purification (38.2 mg, 29\%). RPHPLC: $t_{\mathrm{R}}=6.17 \mathrm{MS}(\mathrm{ES}+)$ : calc. for $\mathrm{C}_{63} \mathrm{H}_{73} \mathrm{~N}_{19} \mathrm{O}_{24} \mathrm{~S}: 1511.48$, found: 1512.00 .
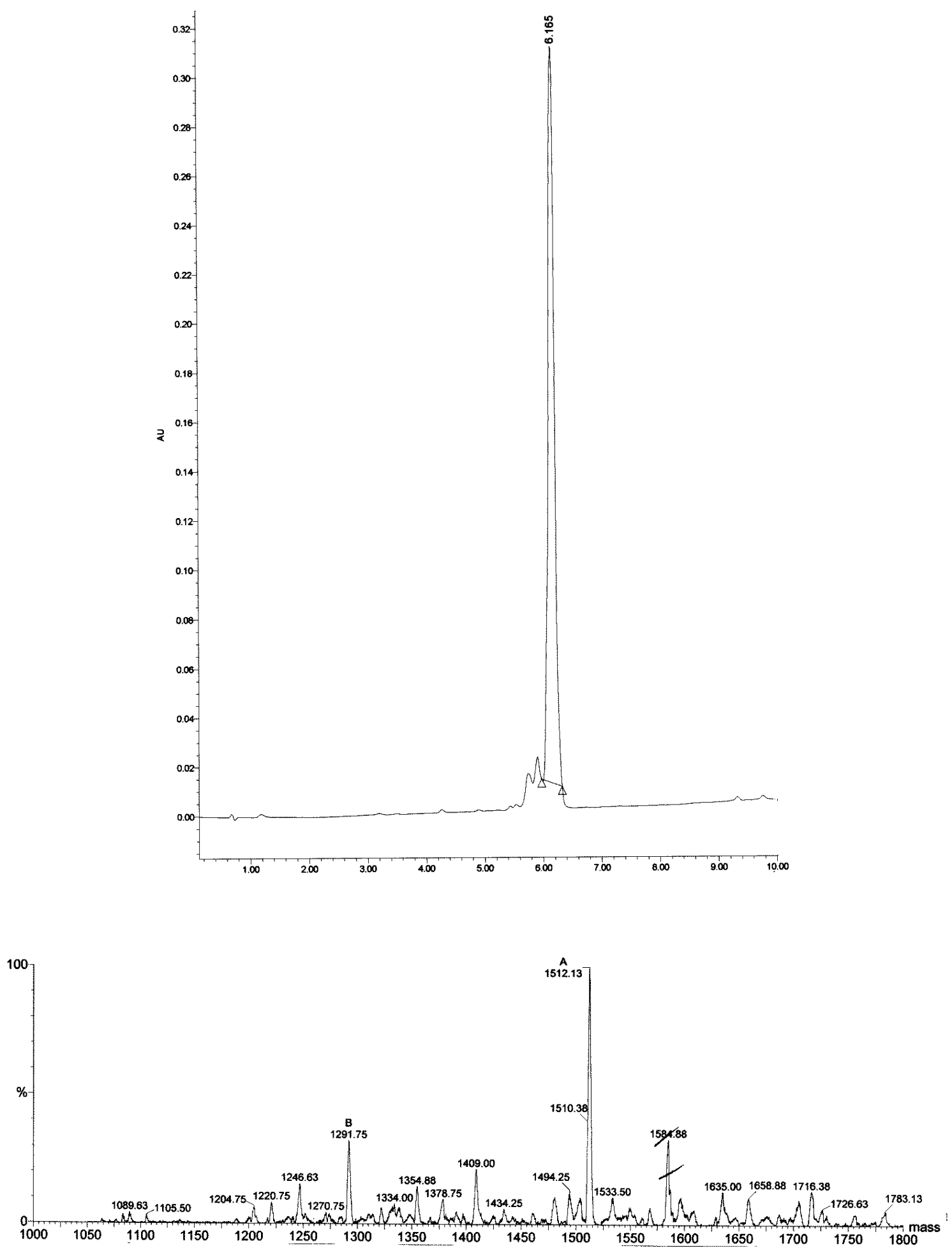


\section{Dendrimer E}

Starting with $100 \mathrm{mg}$ of Rink amide resin $(0.61 \mathrm{mmol} / \mathrm{g})$, the sequence ((Ac-His $)_{2}$-B-Asp $)_{2}$-B-Cys-Ser$\mathrm{NH}_{2}$ was obtained as colorless foamy solid after preparative HPLC purification $(10.0 \mathrm{mg}, 11 \%)$. RPHPLC: $t_{\mathrm{R}}=5.87 \mathrm{MS}(\mathrm{ES}+)$ : calc. for $\mathrm{C}_{60} \mathrm{H}_{71} \mathrm{~N}_{17} \mathrm{O}_{25} \mathrm{~S}: 1555.54$, found: 1555.88 .
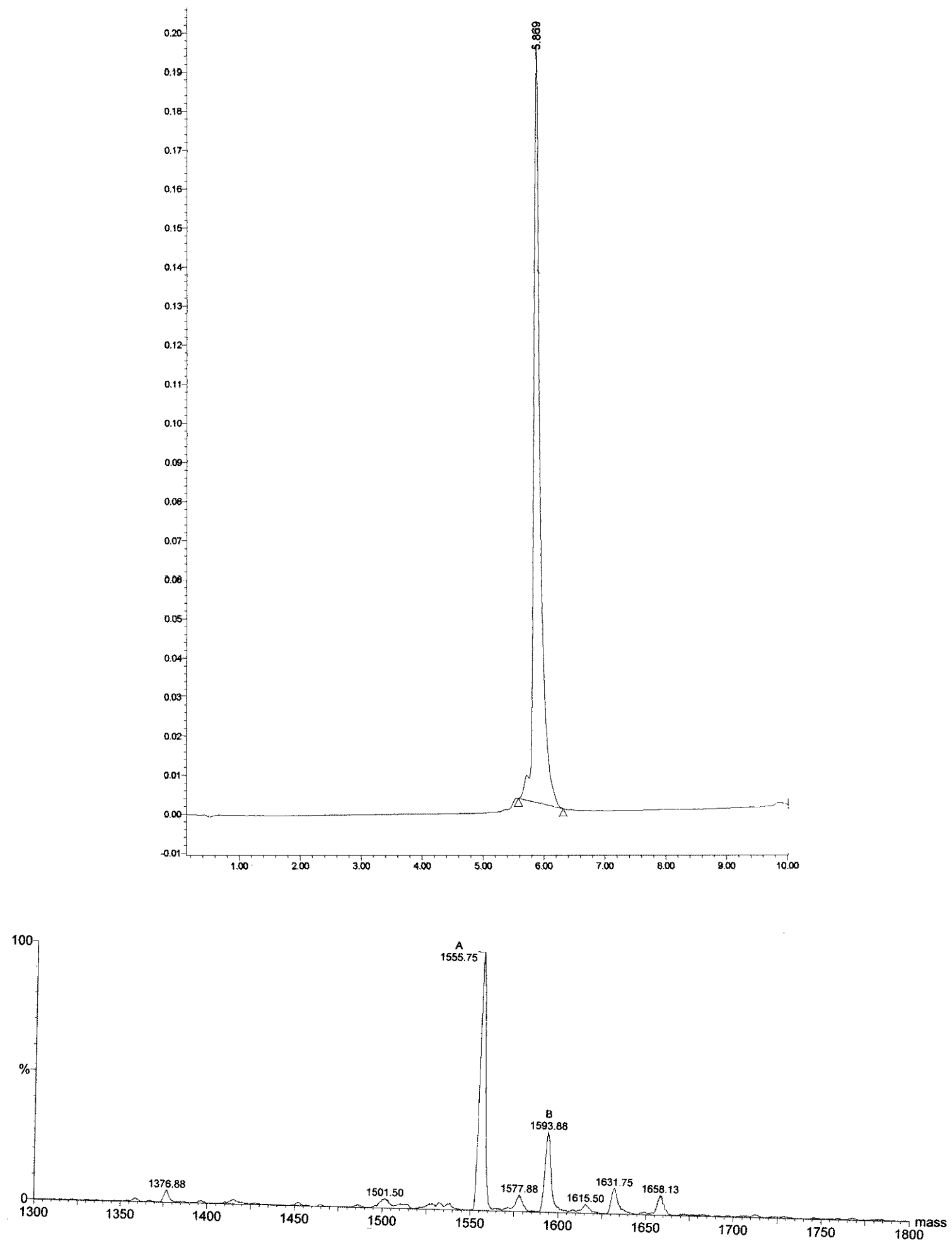


\section{Dendrimer F}

Starting with $200 \mathrm{mg}$ of Rink amide resin $(0.61 \mathrm{mmol} / \mathrm{g})$, the sequence ((Ac-His $)_{2}$-B-Ser $)_{2}$-B-Cys-Asp$\mathrm{NH}_{2}$ was obtained as colorless foamy solid after preparative HPLC purification $(30.0 \mathrm{mg}, 16 \%)$. RPHPLC: $t_{\mathrm{R}}=5.76 \mathrm{MS}(\mathrm{ES}+)$ : calc. for $\mathrm{C}_{66} \mathrm{H}_{77} \mathrm{~N}_{23} \mathrm{O}_{19} \mathrm{~S}: 1527.55$, found: 1528.13 .
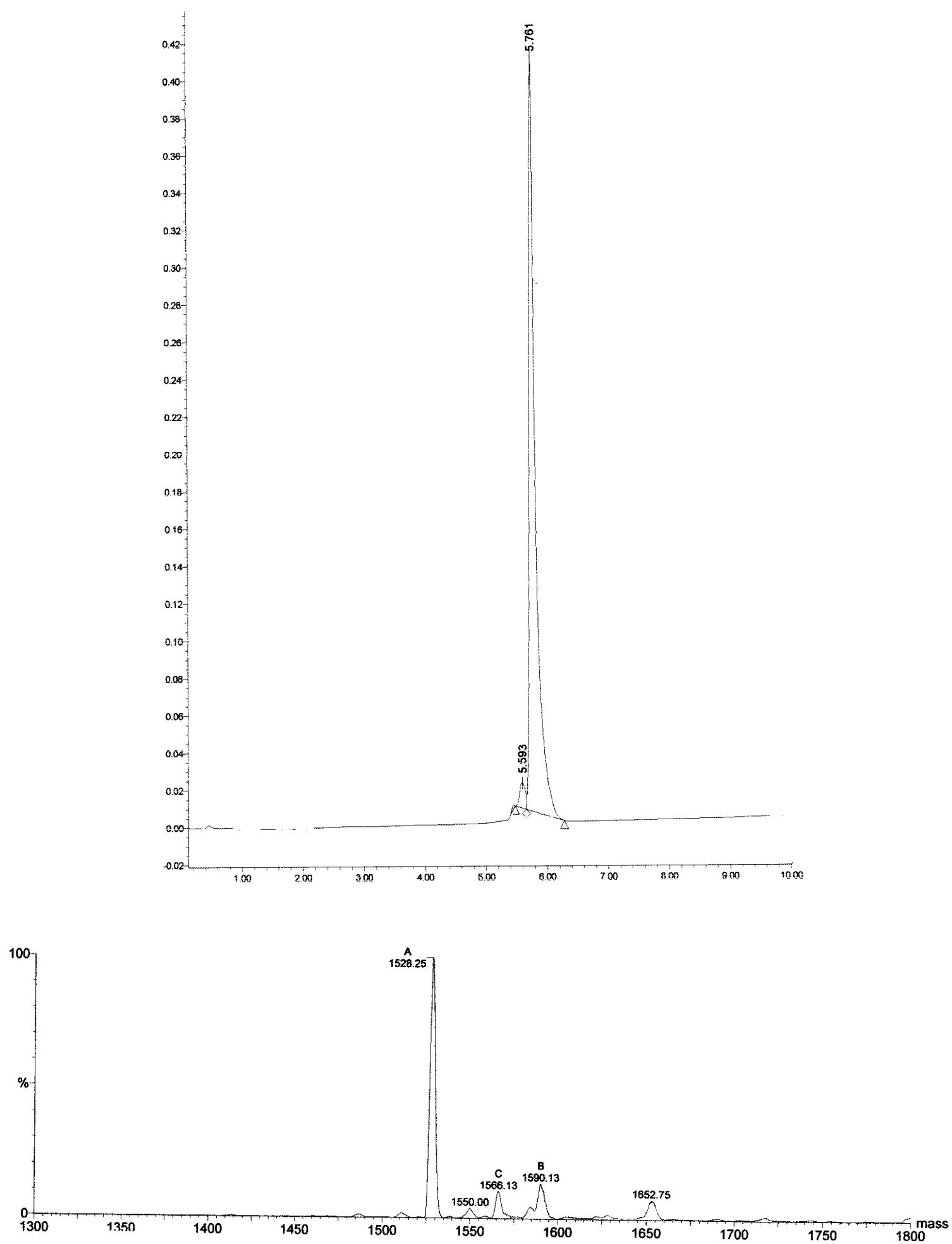


\section{Dendrimer G}

Starting with $150 \mathrm{mg}$ of Rink amide resin $(0.61 \mathrm{mmol} / \mathrm{g})$, the sequence ((Ac-Asp $)_{2}$-B-His $)_{2}$-B-Cys-Ala$\mathrm{NH}_{2}$ was obtained as colorless foamy solid after preparative HPLC purification (19 mg, 14\%). RPHPLC: $t_{\mathrm{R}}=6.23 \mathrm{MS}(\mathrm{ES}+)$ : calc. for $\mathrm{C}_{63} \mathrm{H}_{73} \mathrm{~N}_{19} \mathrm{O}_{23} \mathrm{~S}: 1495.48$, found: 1495.63 .
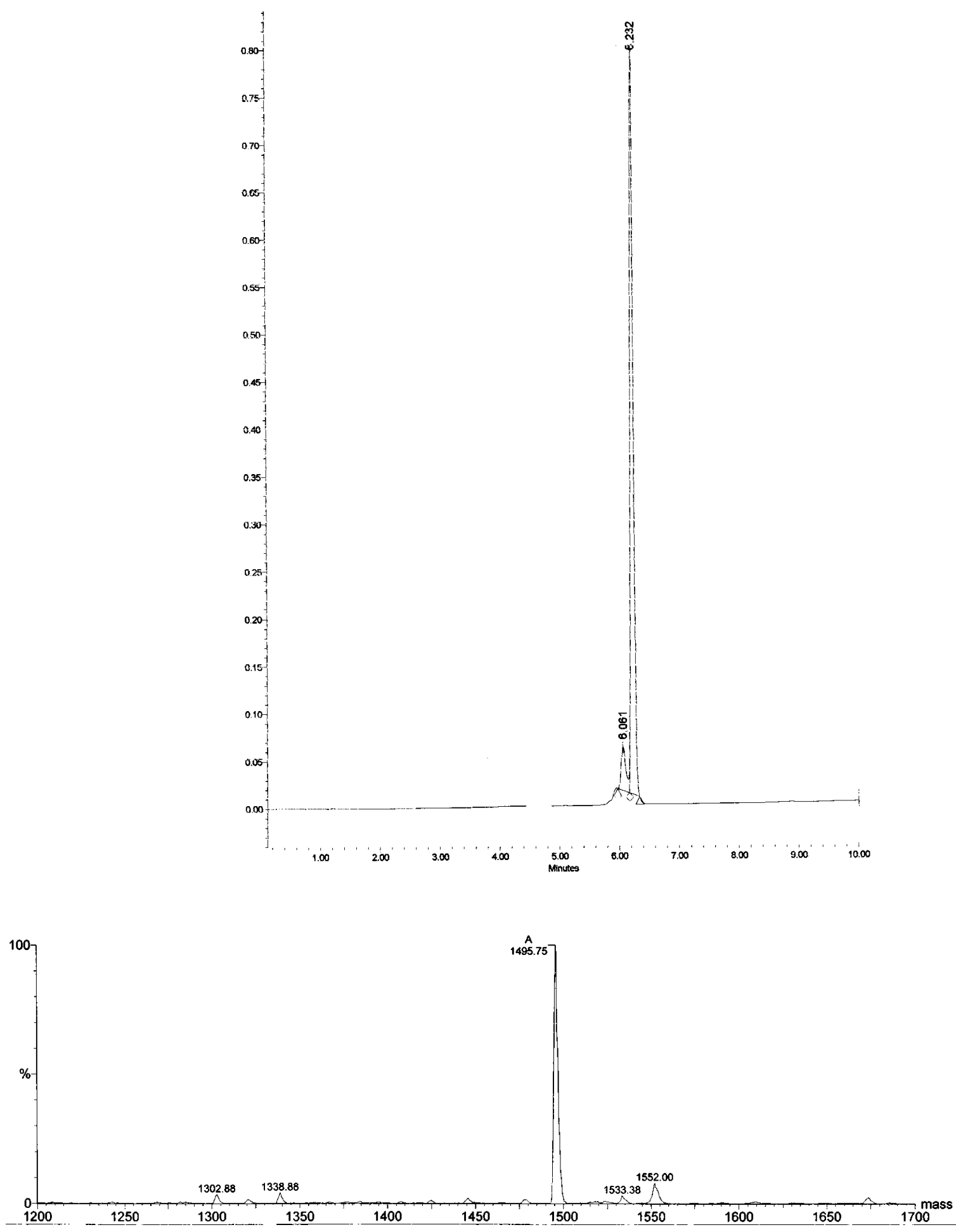


\section{Dendrimer $\mathbf{H}$}

Starting with $100 \mathrm{mg}$ of Rink amide resin $(0.61 \mathrm{mmol} / \mathrm{g})$, the sequence ((Ac-Asp $)_{2}$-B-Ala $)_{2}$-B-Cys-Ser$\mathrm{NH}_{2}$ was obtained as colorless foamy solid after preparative HPLC purification $(8.5 \mathrm{mg}, 10 \%)$. RPHPLC: $t_{\mathrm{R}}=7.36 \mathrm{MS}(\mathrm{ES}+)$ : calc. for $\mathrm{C}_{57} \mathrm{H}_{69} \mathrm{~N}_{15} \mathrm{O}_{24} \mathrm{~S}: 1379.44$, found: 1381.38 .
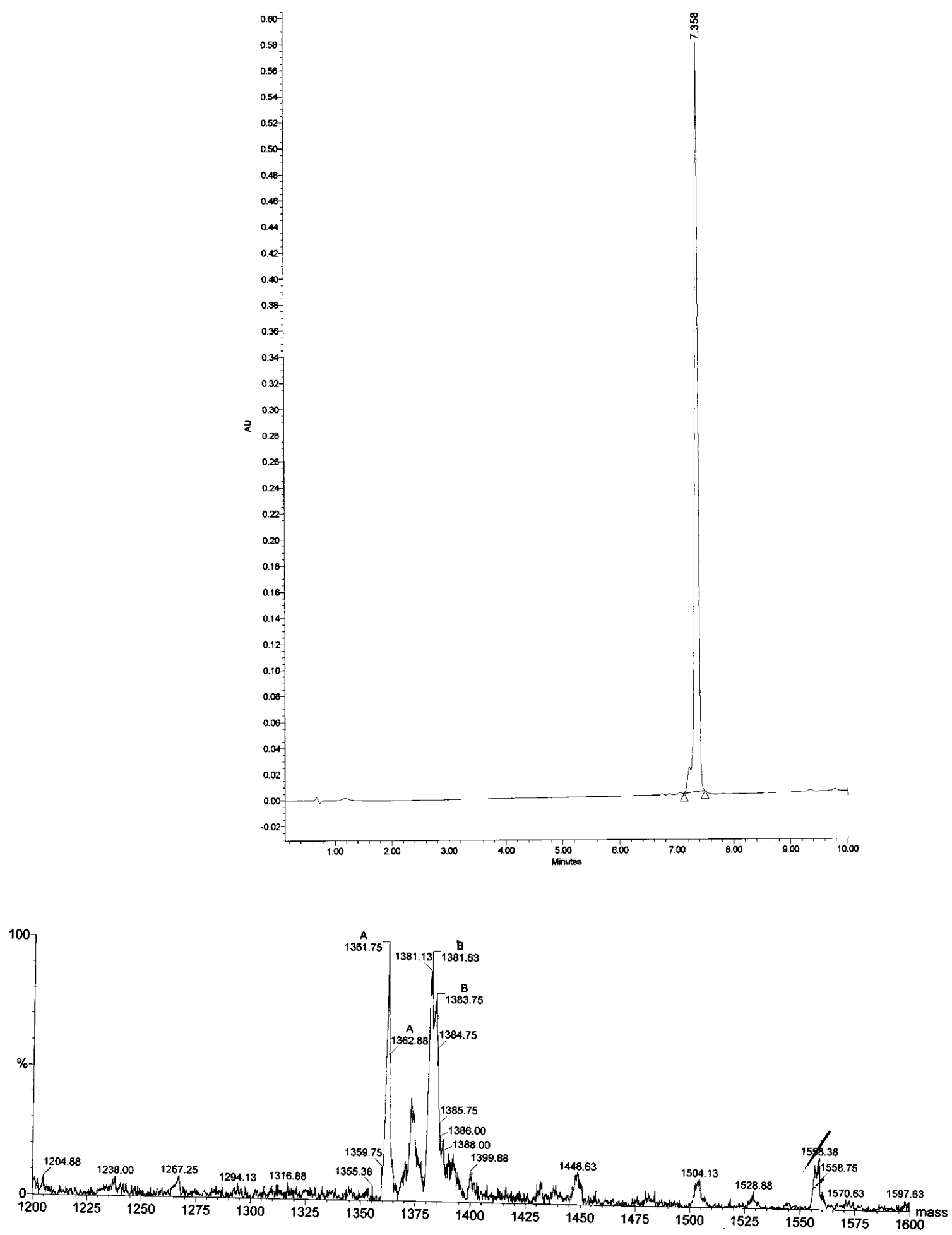


\section{Dendrimer K}

Starting with $150 \mathrm{mg}$ of Rink amide resin $(0.61 \mathrm{mmol} / \mathrm{g})$, the sequence $\left((\mathrm{Ac}-\mathrm{Asp})_{2} \text {-B-His)-((Ac-Asp }\right)_{2}$ B-Ala)-B-Cys-Ala- $\mathrm{NH}_{2}$ was obtained as colorless foamy solid after preparative HPLC purification (12.6 mg, 10\%). RP-HPLC: $t_{\mathrm{R}}=6.68 \mathrm{MS}$ (ES+): calc. for $\mathrm{C}_{60} \mathrm{H}_{71} \mathrm{~N}_{17} \mathrm{O}_{24} \mathrm{~S}: 1445.46$, found: 1445.63 .
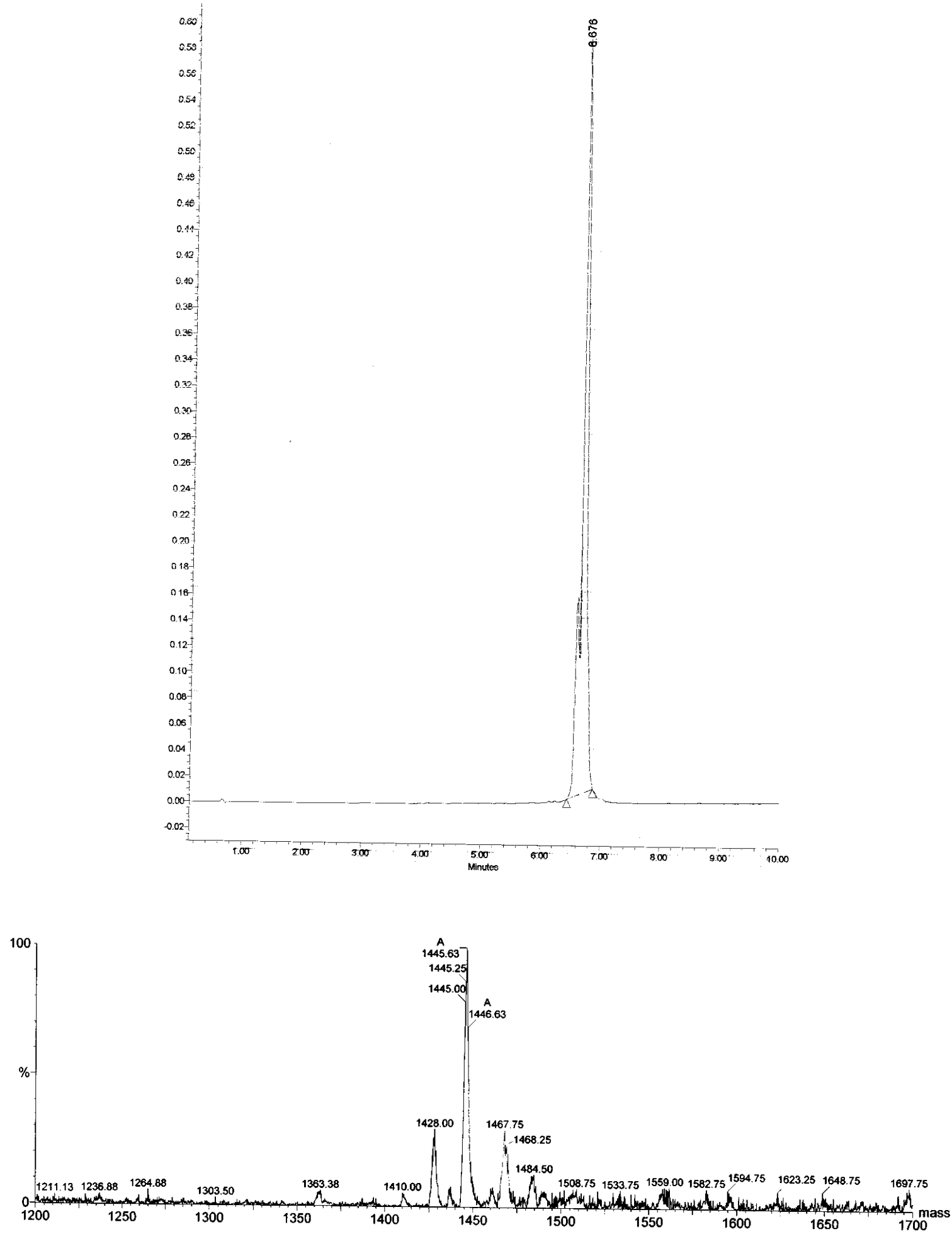


\section{Dendrimer J}

Starting with $50 \mathrm{mg}$ of Rink amide resin $(0.61 \mathrm{mmol} / \mathrm{g})$, the sequence ((Ac-His $)_{2}$-B-Ala $)_{2}$-B-Cys-Ala$\mathrm{NH}_{2}$ was obtained as colorless foamy solid after preparative HPLC purification (5 mg, 11\%). RPHPLC: $t_{\mathrm{R}}=6.61 \mathrm{MS}(\mathrm{ES}+)$ : calc. for $\mathrm{C}_{65} \mathrm{H}_{77} \mathrm{~N}_{23} \mathrm{O}_{15} \mathrm{~S}: 1451.57$, found: 1452.25 .
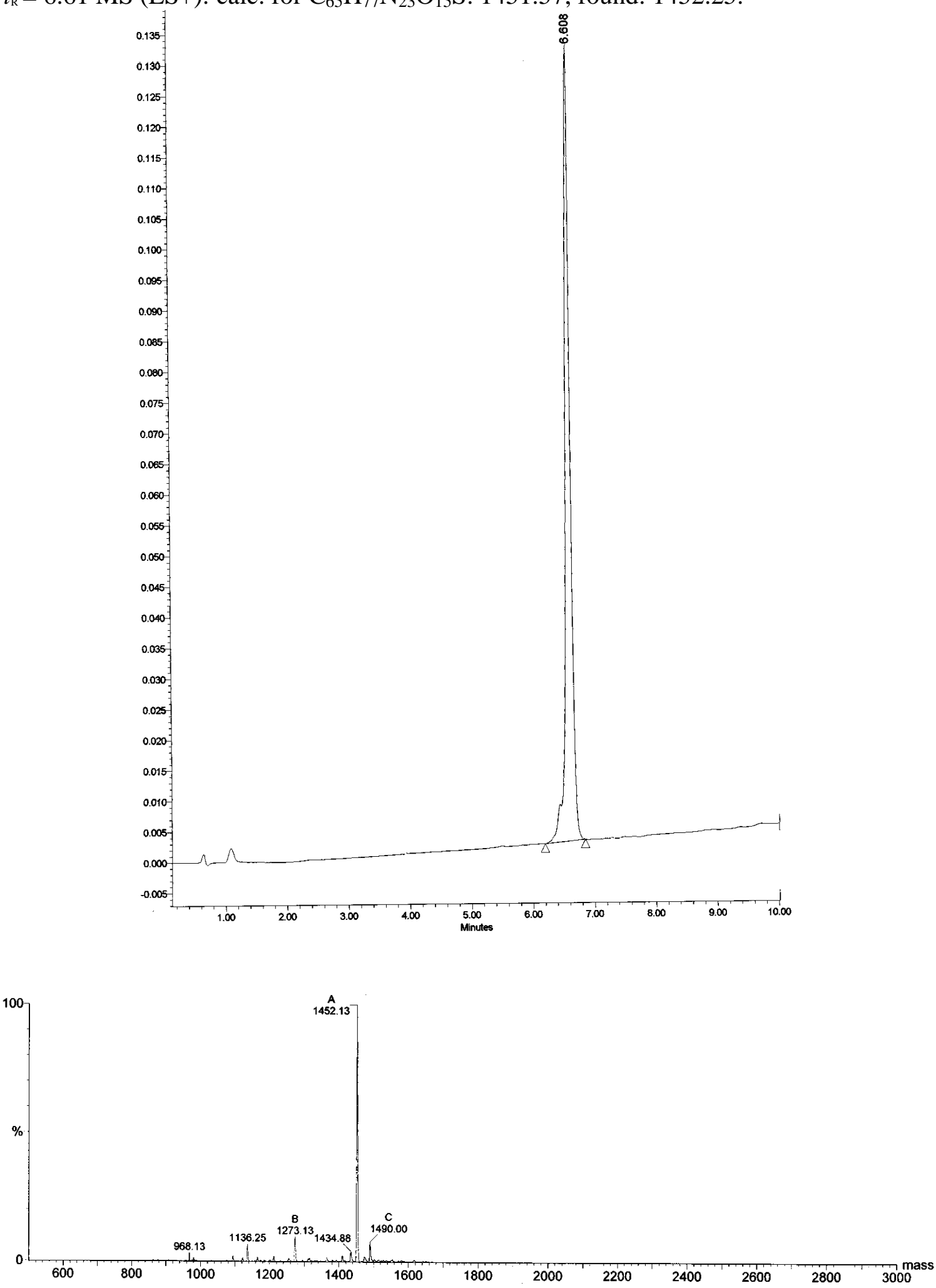


\section{Dendrimer AA}

$0.5 \mathrm{mg}, 50 \%$, RP-HPLC: $t_{\mathrm{R}}=6.31 \mathrm{MS}\left(\mathrm{ES}+\right.$ ): calc. for $\mathrm{C}_{116} \mathrm{H}_{140} \mathrm{~N}_{34 \mathrm{O}_{46}} \mathrm{~S}_{2}: 2810.7$, found: 2810.00 .
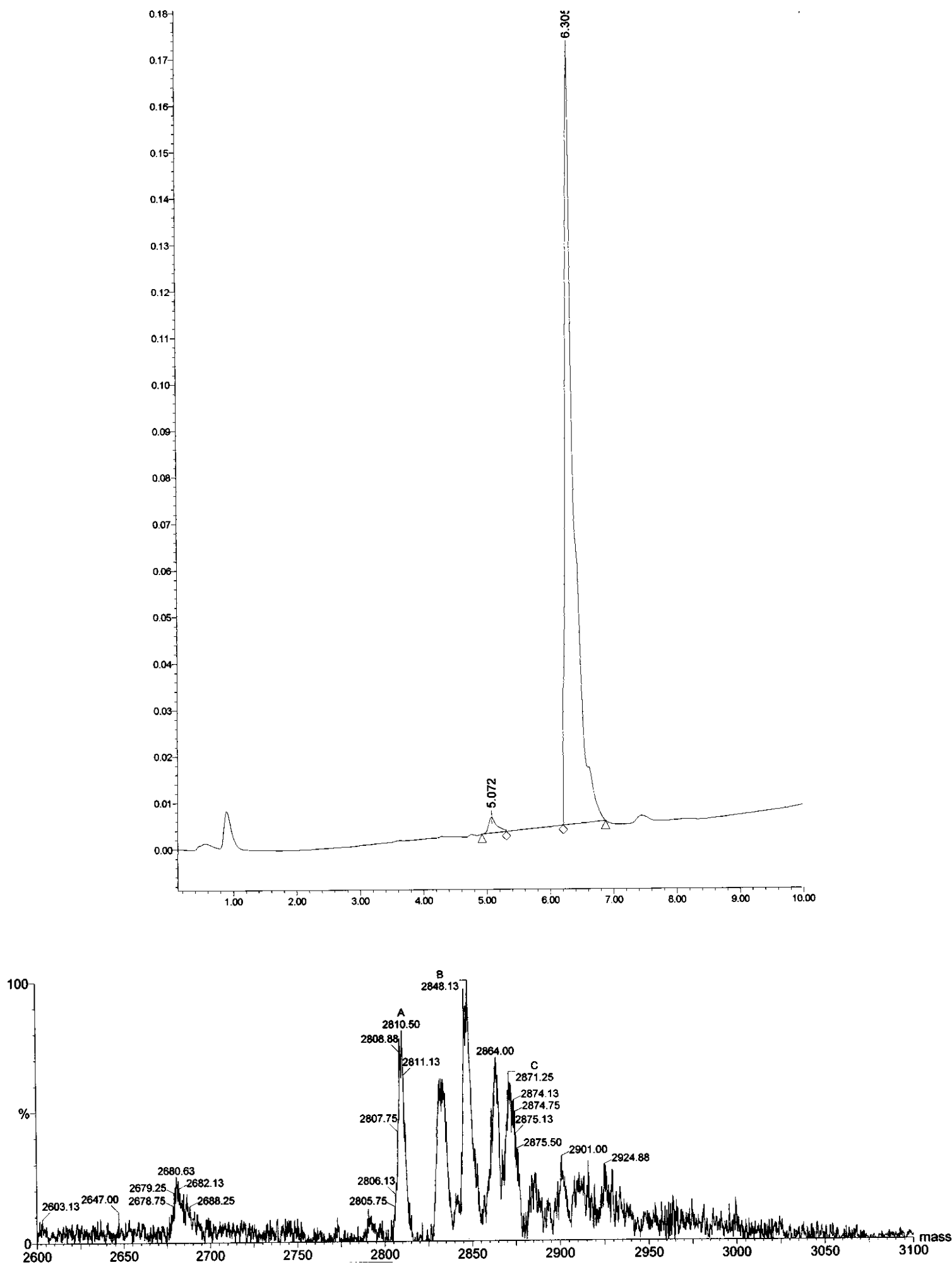


\section{Dendrimer AB}

$0.3 \mathrm{mg}, 15 \%$, RP-HPLC: $t_{\mathrm{R}}=6.12 \mathrm{MS}$ (ES+): calc. for $\mathrm{C}_{119} \mathrm{H}_{146} \mathrm{~N}_{36} \mathrm{O}_{44} \mathrm{~S}_{2}: 2832.83$, found: 2831.88 .
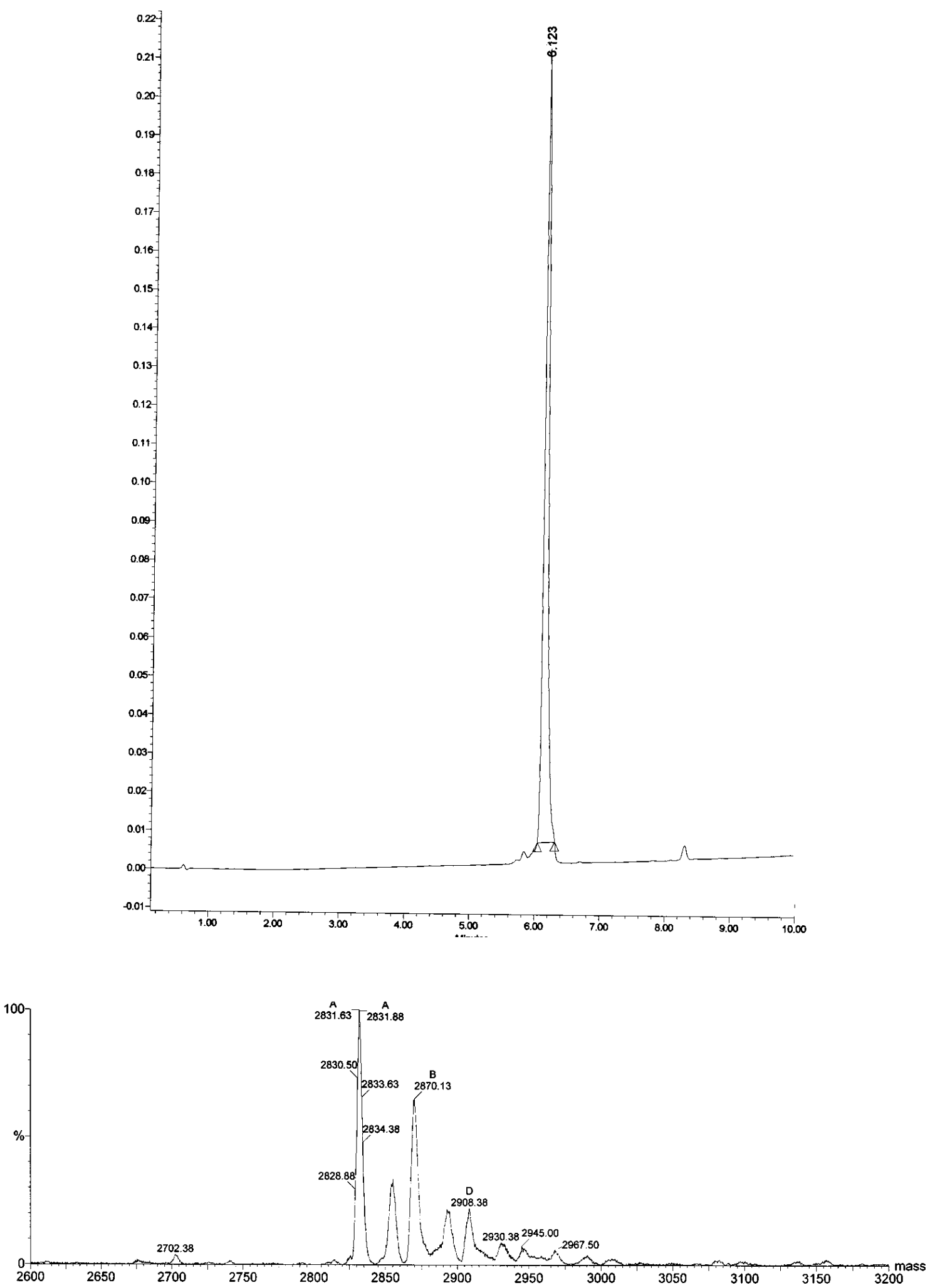


\section{Dendrimer AC}

$0.3 \mathrm{mg}, 29 \%$, RP-HPLC: $t_{\mathrm{R}}=6.67 \mathrm{MS}$ (ES+): calc. for $\mathrm{C}_{118} \mathrm{H}_{140} \mathrm{~N}_{34} \mathrm{O}_{48} \mathrm{~S}_{2}: 2865.80$, found: 2865.88 .
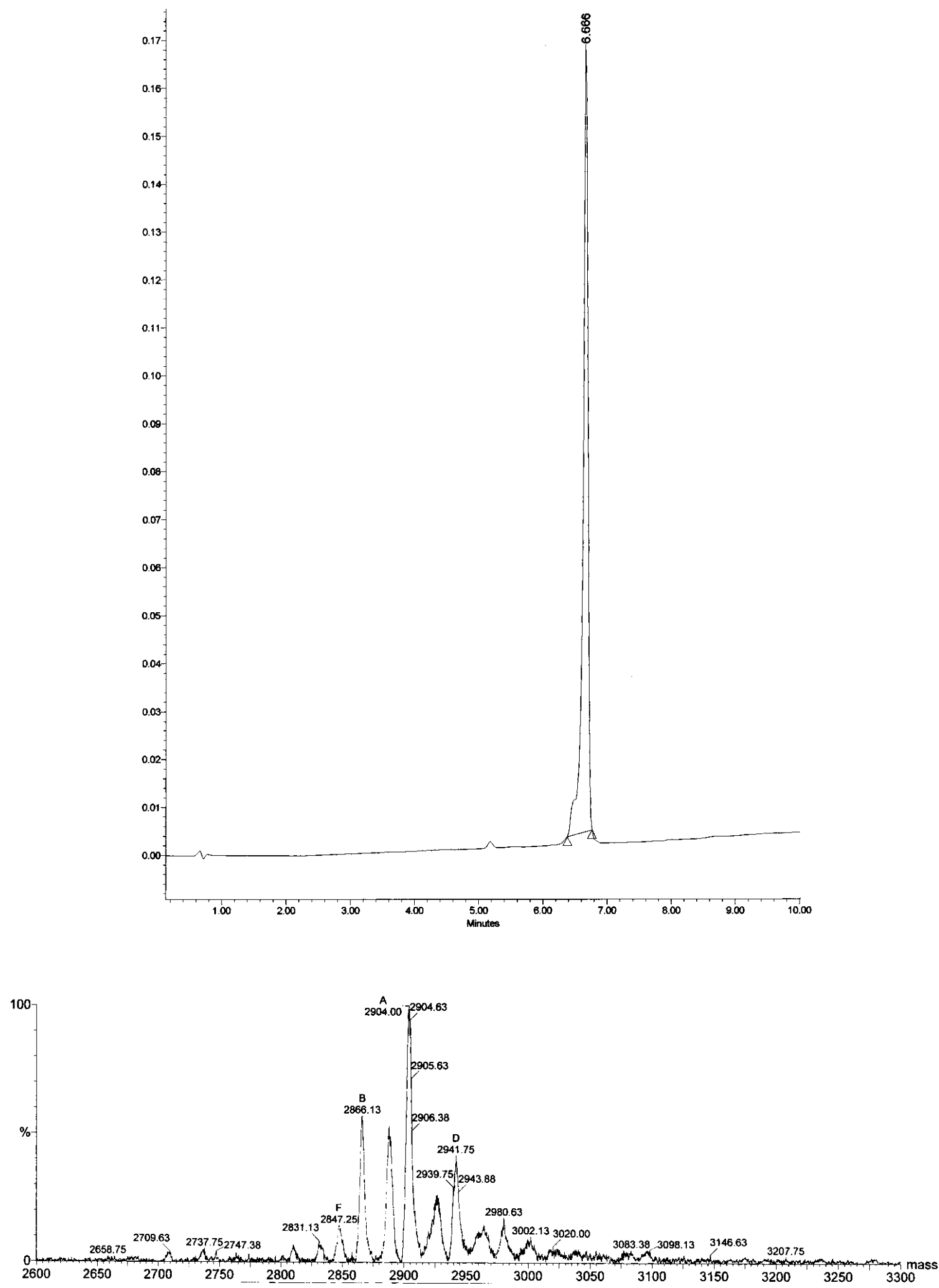


\section{Dendrimer AD}

$0.2 \mathrm{mg}, 19 \%$, RP-HPLC: $t_{\mathrm{R}}=5.88 \mathrm{MS}$ (ES+): calc. for $\mathrm{C}_{121} \mathrm{H}_{142} \mathrm{~N}_{36} \mathrm{O}_{47} \mathrm{~S}_{2}: 2915.83$, found: 2915.50 .
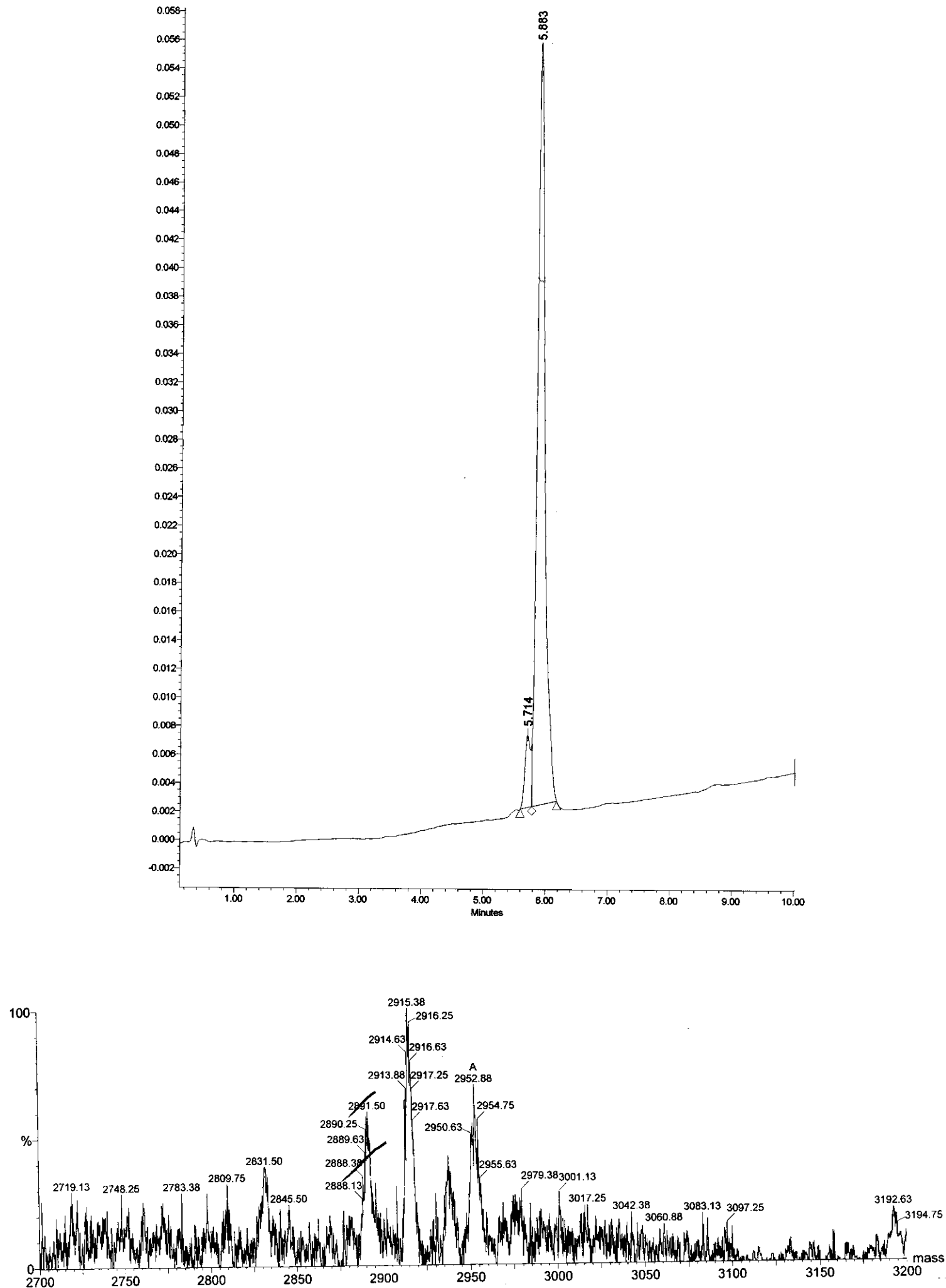


\section{Dendrimer AE}

$0.5 \mathrm{mg}, 42 \%$, RP-HPLC: $t_{\mathrm{R}}=5.52 \mathrm{MS}$ (ES+): calc. for $\mathrm{C}_{125} \mathrm{H}_{146} \mathrm{~N}_{40} \mathrm{O}_{43} \mathrm{~S}_{2}: 2959.89$, found: 2960.50 .
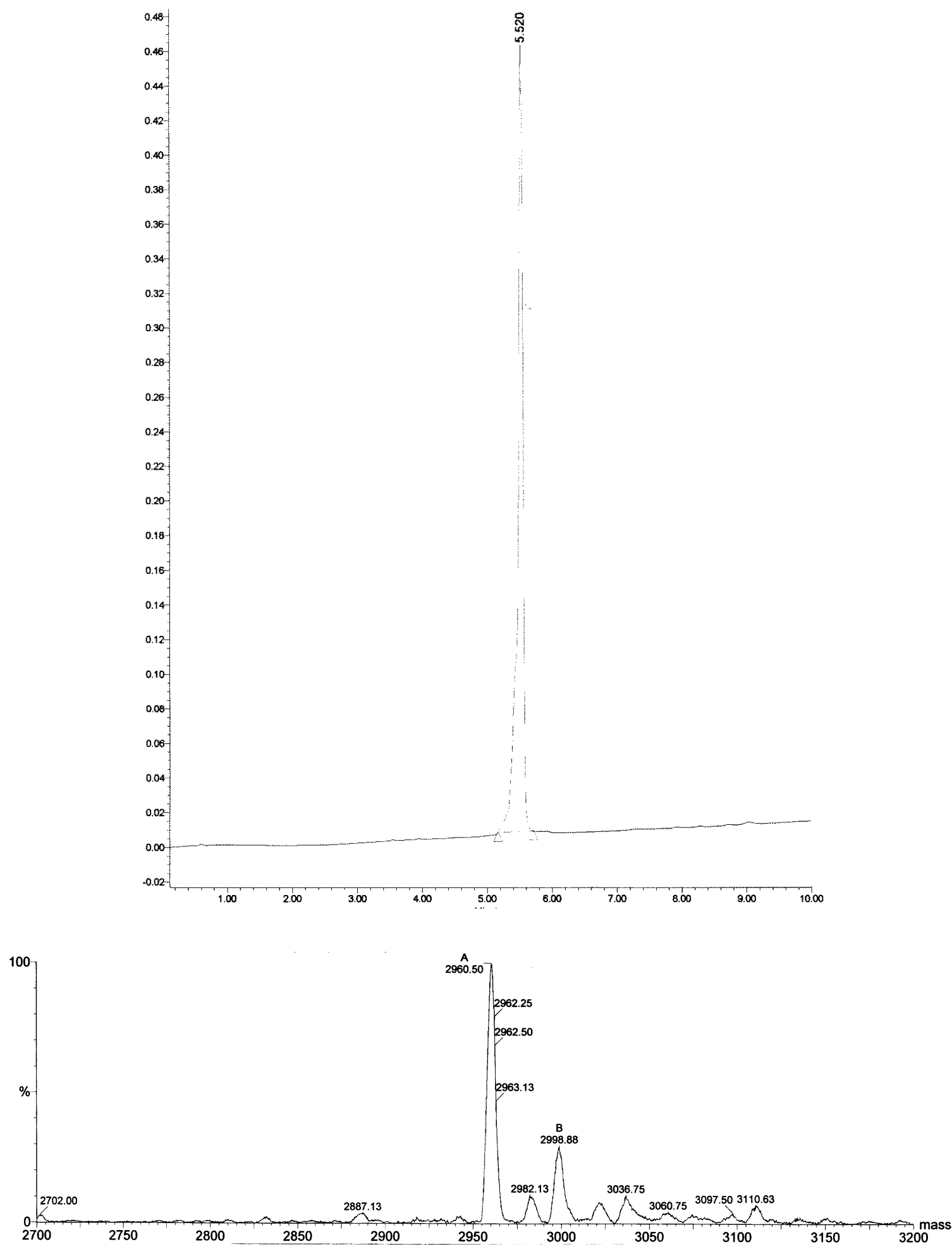


\section{Dendrimer AF}

$0.5 \mathrm{mg}, 48 \%$, RP-HPLC: $t_{\mathrm{R}}=6.51 \mathrm{MS}$ (ES+): calc. for $\mathrm{C}_{124} \mathrm{H}_{146} \mathrm{~N}_{40} \mathrm{O}_{42} \mathrm{~S}_{2}: 2931.90$, found: 2931.75 .
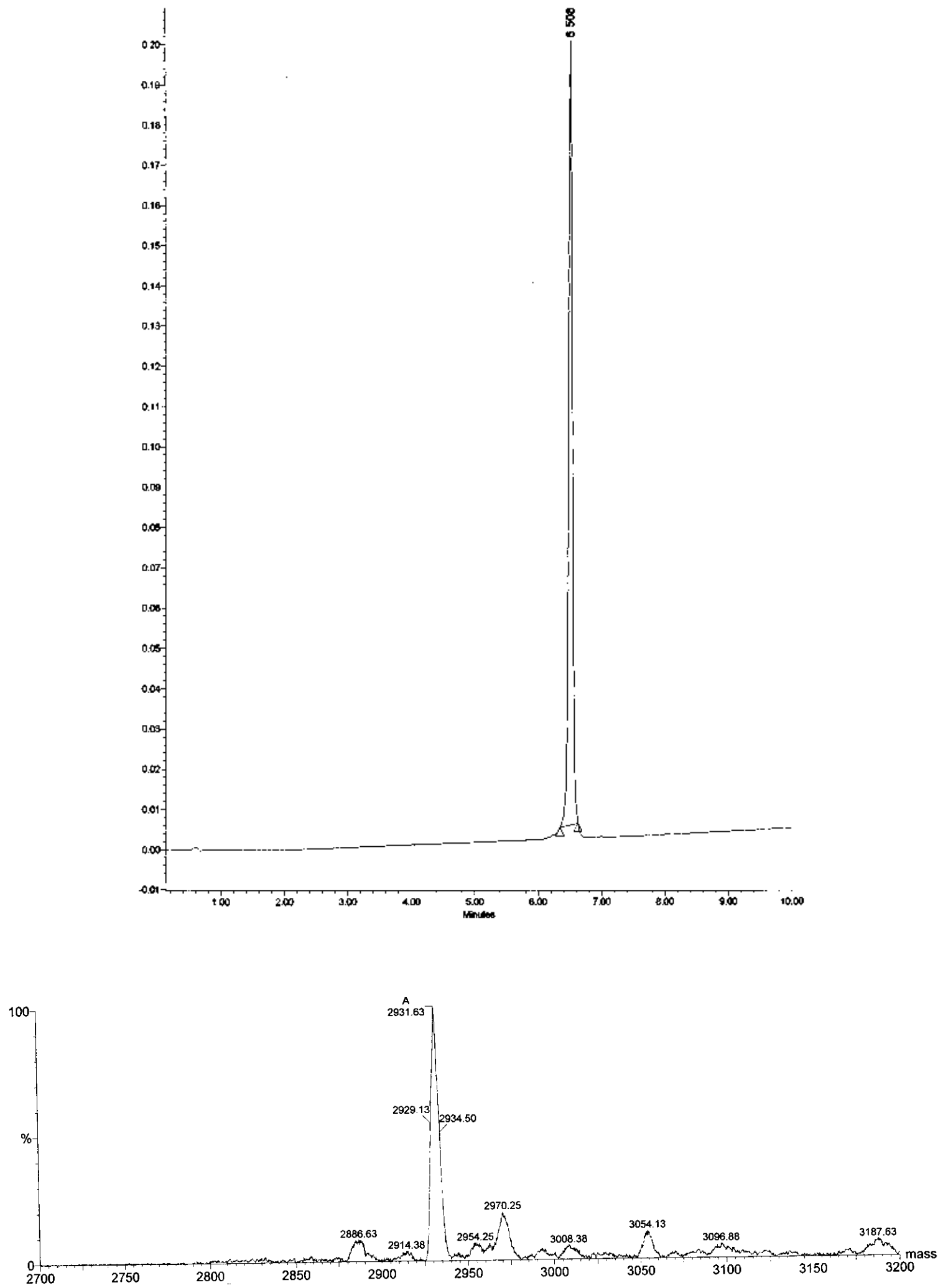


\section{Dendrimer BB}

$0.4 \mathrm{mg}, 40 \%$, RP-HPLC: $t_{\mathrm{R}}=5.55 \mathrm{MS}$ (ES+): calc. for $\mathrm{C}_{172} \mathrm{H}_{222} \mathrm{~N}_{42} \mathrm{O}_{72} \mathrm{~S}_{2}: 2854.96$, found: 2854.13 .
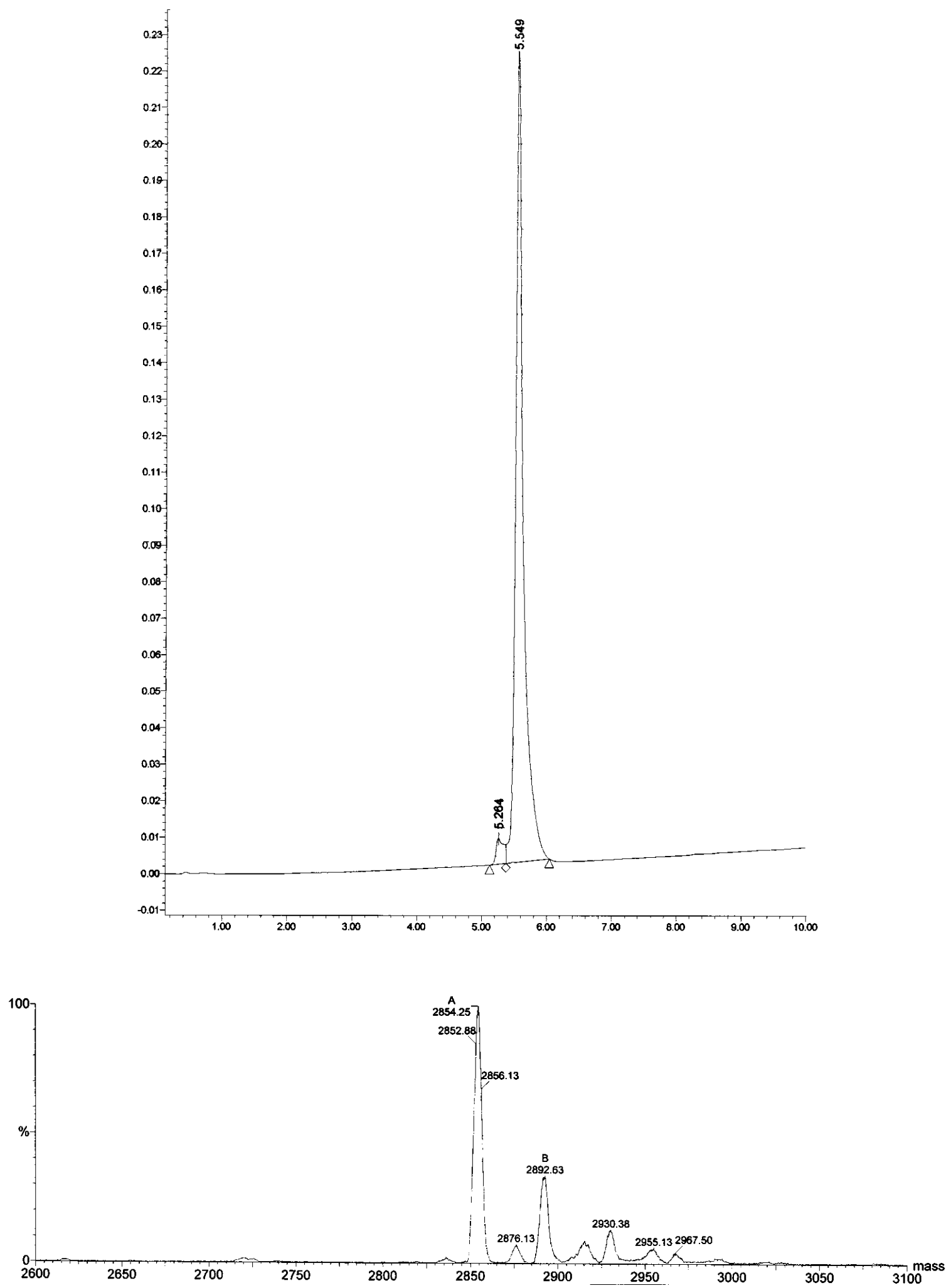


\section{Dendrimer BC}

$0.3 \mathrm{mg}, 30 \%$, RP-HPLC: $t_{\mathrm{R}}=6.15 \mathrm{MS}$ (ES+): calc. for $\mathrm{C}_{121} \mathrm{H}_{146} \mathrm{~N}_{36} \mathrm{O}_{46} \mathrm{~S}_{2}: 2887.93$, found: 2887.88 .
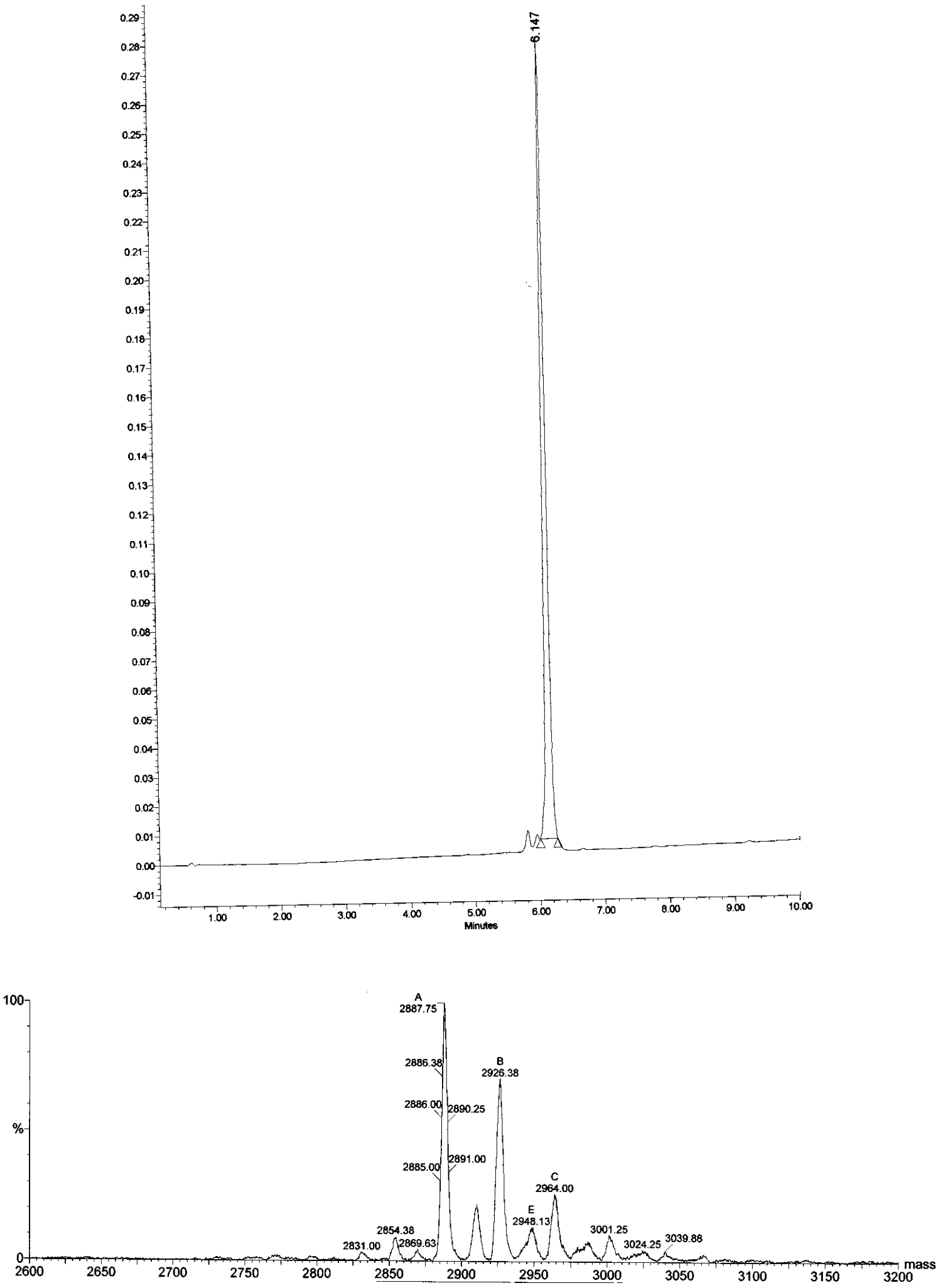


\section{Dendrimer BD}

$0.4 \mathrm{mg}, 41 \%$, RP-HPLC: $t_{\mathrm{R}}=5.55 \mathrm{MS}$ (ES+): calc. for $\mathrm{C}_{124} \mathrm{H}_{148} \mathrm{~N}_{38} \mathrm{O}_{45} \mathrm{~S}_{2}: 2937.96$, found: 2937.88 .
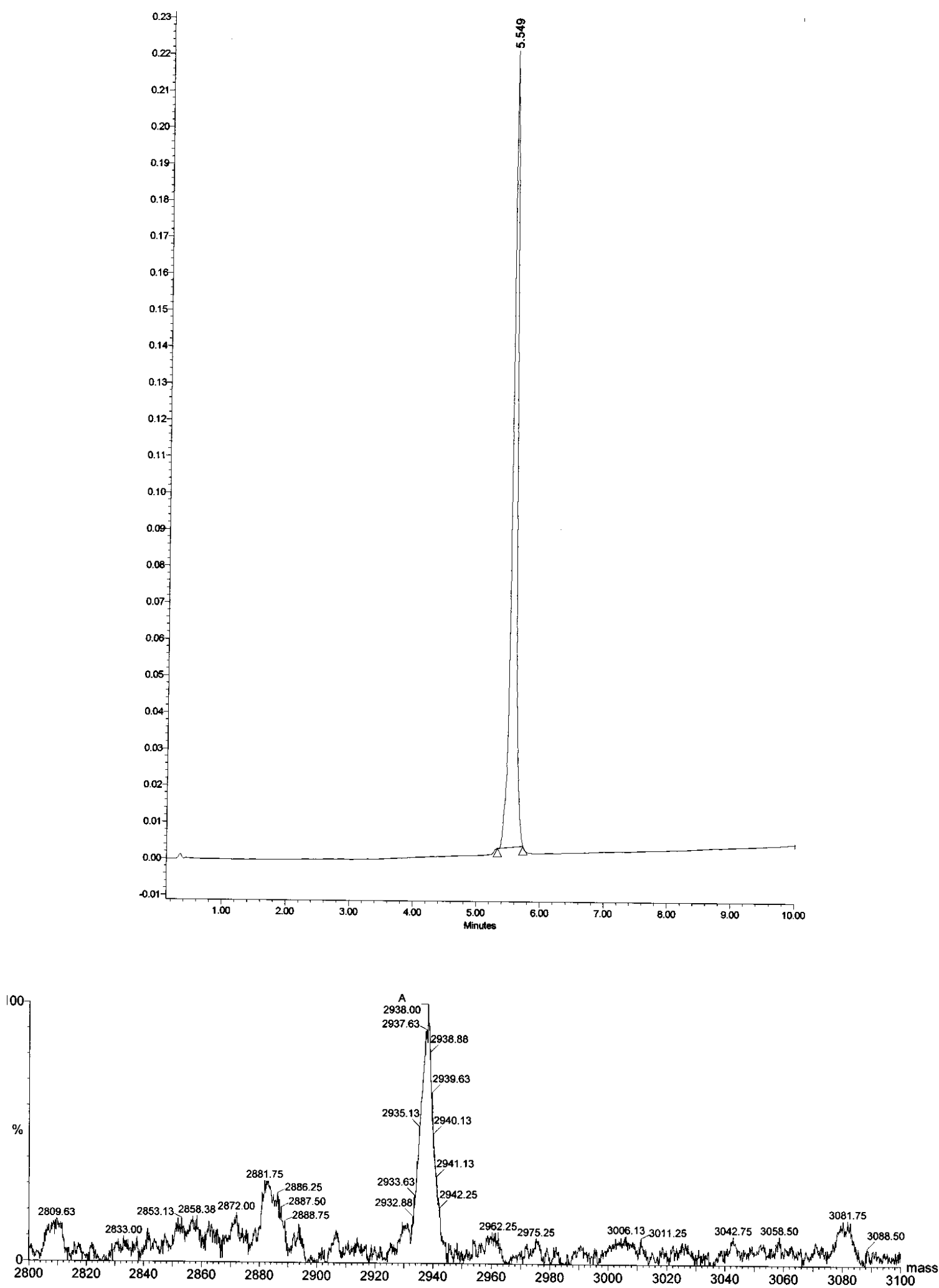


\section{Dendrimer BE}

$0.3 \mathrm{mg}, 30 \%$, RP-HPLC: $t_{\mathrm{R}}=6.82 \mathrm{MS}$ (ES+): calc. for $\mathrm{C}_{128} \mathrm{H}_{152} \mathrm{~N}_{42} \mathrm{O}_{41} \mathrm{~S}_{2}: 2982.02$, found: 2981.50 .
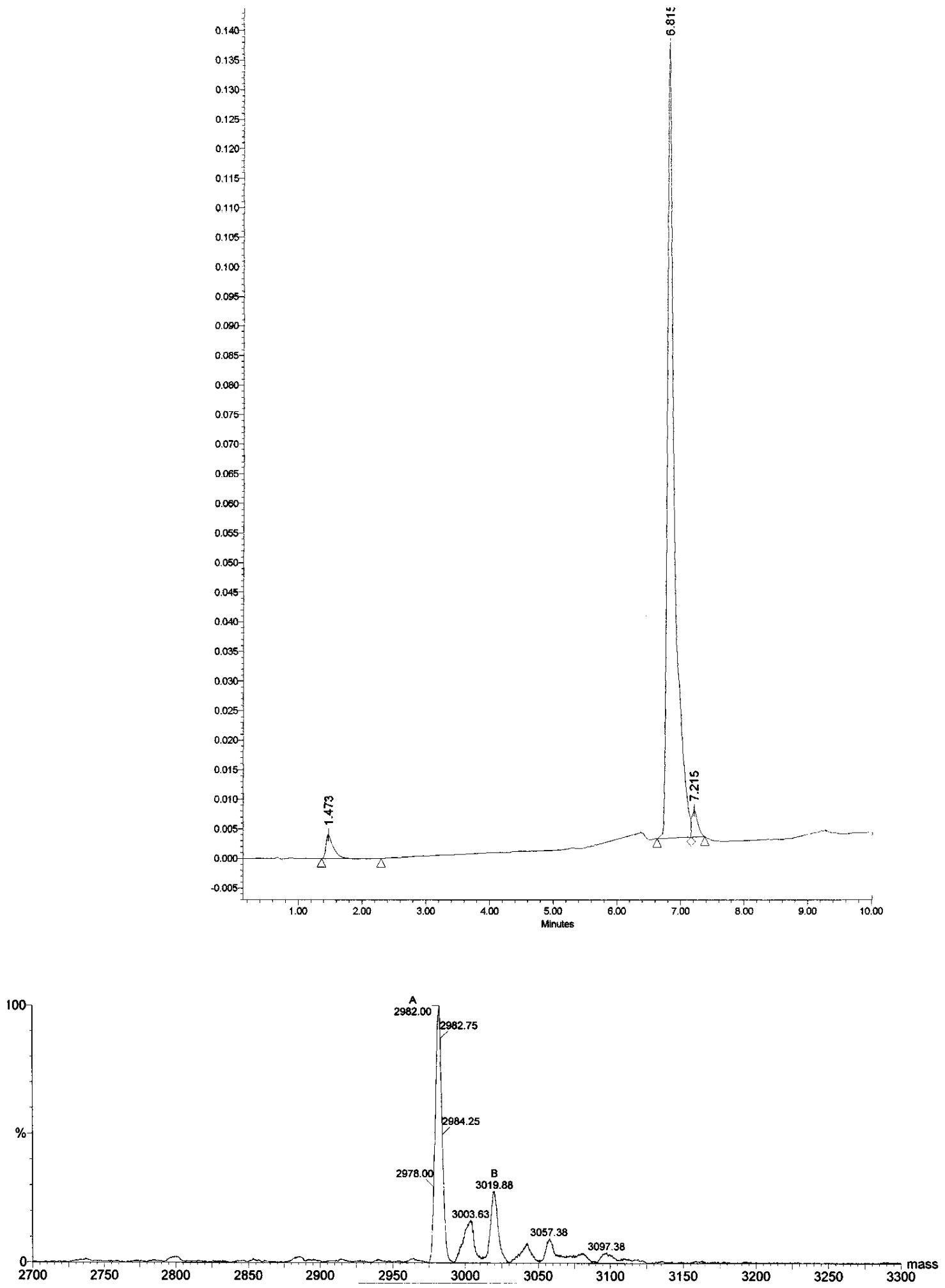


\section{Dendrimer BF}

$0.4 \mathrm{mg}$, 40\%, RP-HPLC: $t_{\mathrm{R}}=5.94 \mathrm{MS}$ (ES+): calc. for $\mathrm{C}_{127} \mathrm{H}_{152} \mathrm{~N}_{42} \mathrm{O}_{40} \mathrm{~S}_{2}$ : 2954.03, found: 2953.63.
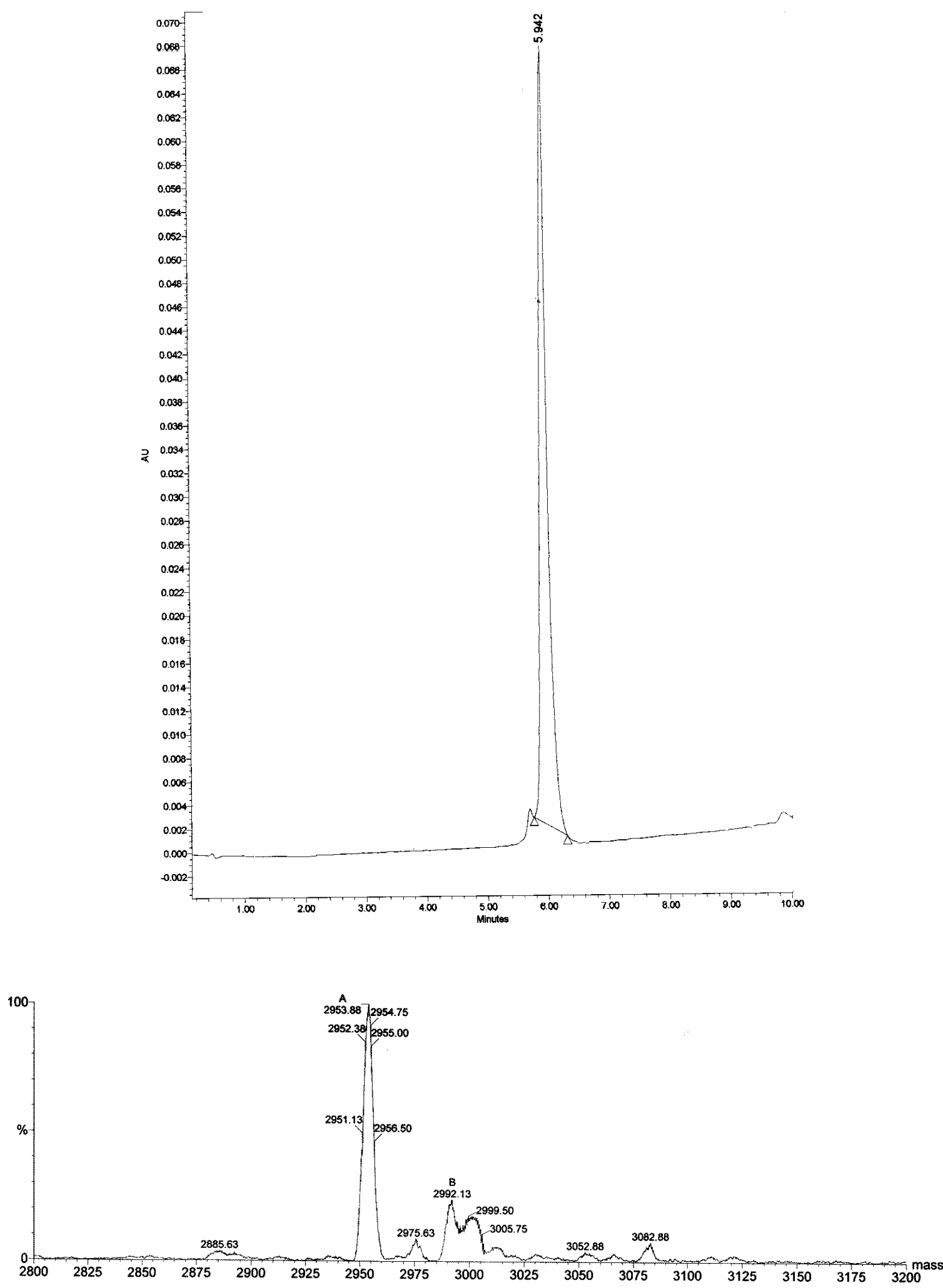


\section{Dendrimer CC}

$0.5 \mathrm{mg}, 50 \%$, RP-HPLC: $t_{\mathrm{R}}=4.27$ (A/B (80:20) to A/B (0:100) in $5 \mathrm{~min}$ ) MS (ES+): calc. for $\mathrm{C}_{120} \mathrm{H}_{140} \mathrm{~N}_{34} \mathrm{O}_{50} \mathrm{~S}_{2}: 2920.89$, found: 2921.88 .
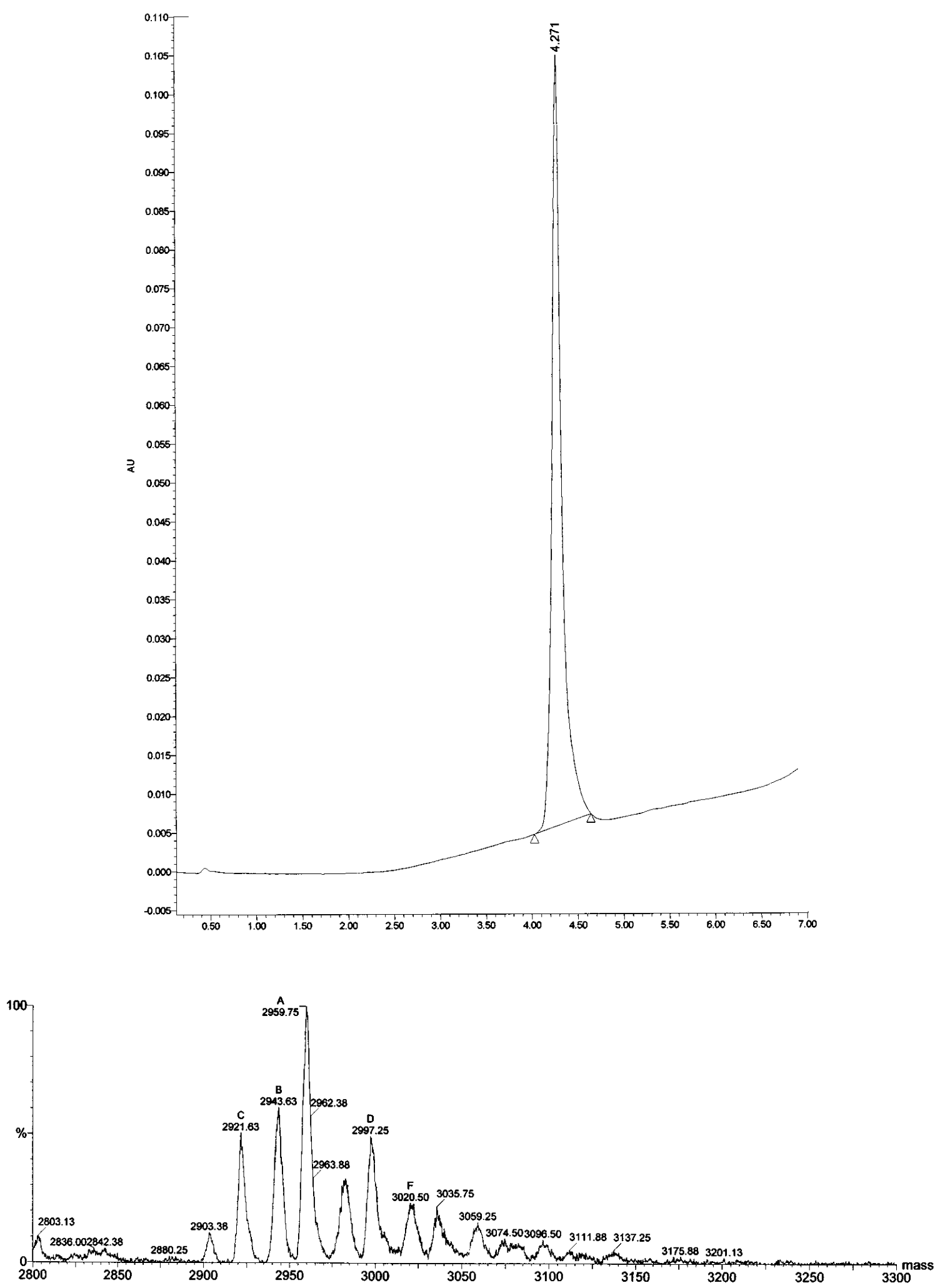


\section{Dendrimer CD}

$0.2 \mathrm{mg}, 20 \%$, RP-HPLC: $t_{\mathrm{R}}=6.94 \mathrm{MS}$ (ES+): calc. for $\mathrm{C}_{123} \mathrm{H}_{142} \mathrm{~N}_{36} \mathrm{O}_{49} \mathrm{~S}_{2}: 2970.93$, found: 2971.88 .
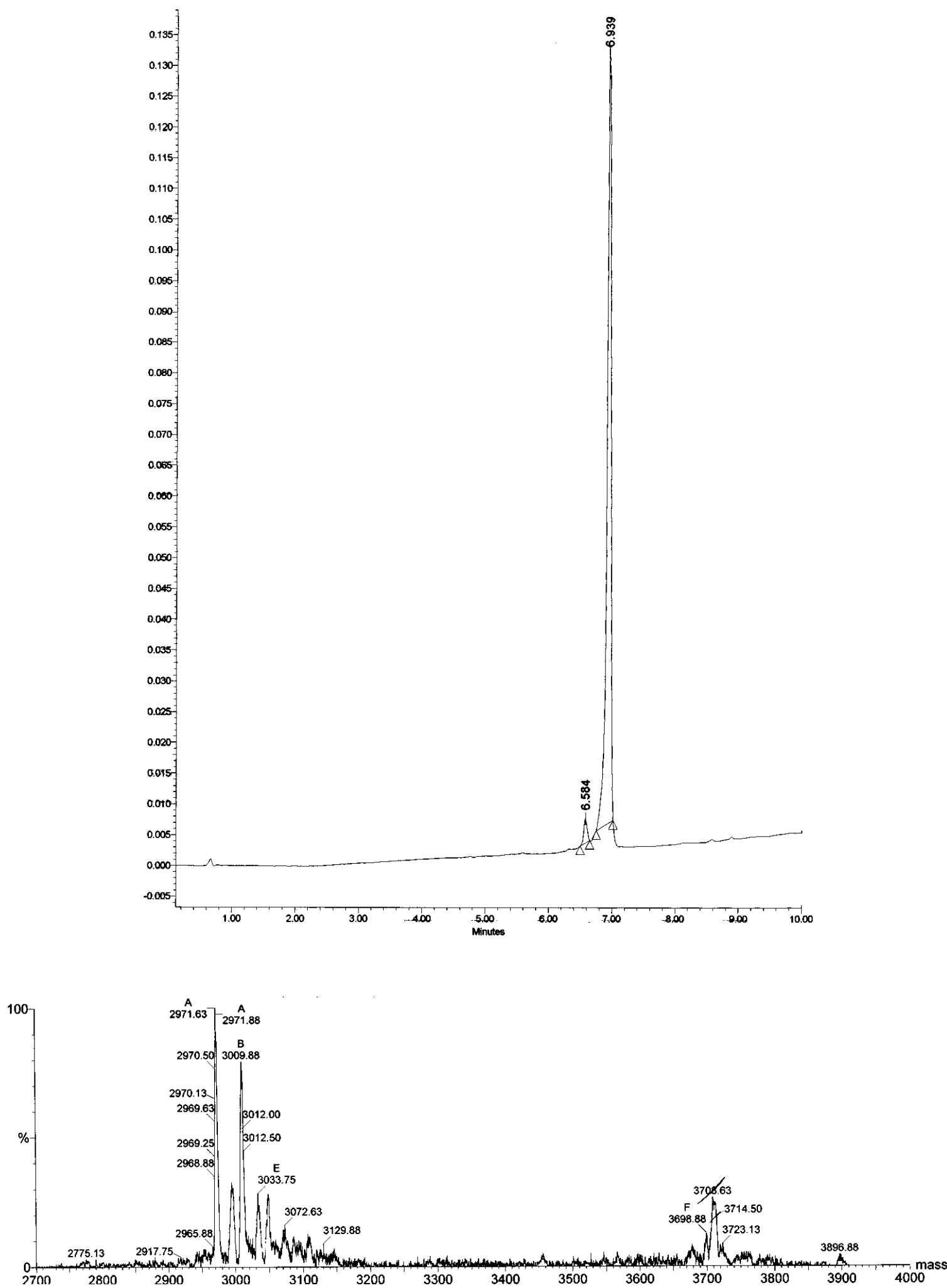


\section{Dendrimer CE}

$0.5 \mathrm{mg}, 26 \%$, RP-HPLC: $t_{\mathrm{R}}=6.46 \mathrm{MS}$ (ES+): calc. for $\mathrm{C}_{127} \mathrm{H}_{146} \mathrm{~N}_{40} \mathrm{O}_{45} \mathrm{~S}_{2}: 3014.99$, found: 3016.25 .
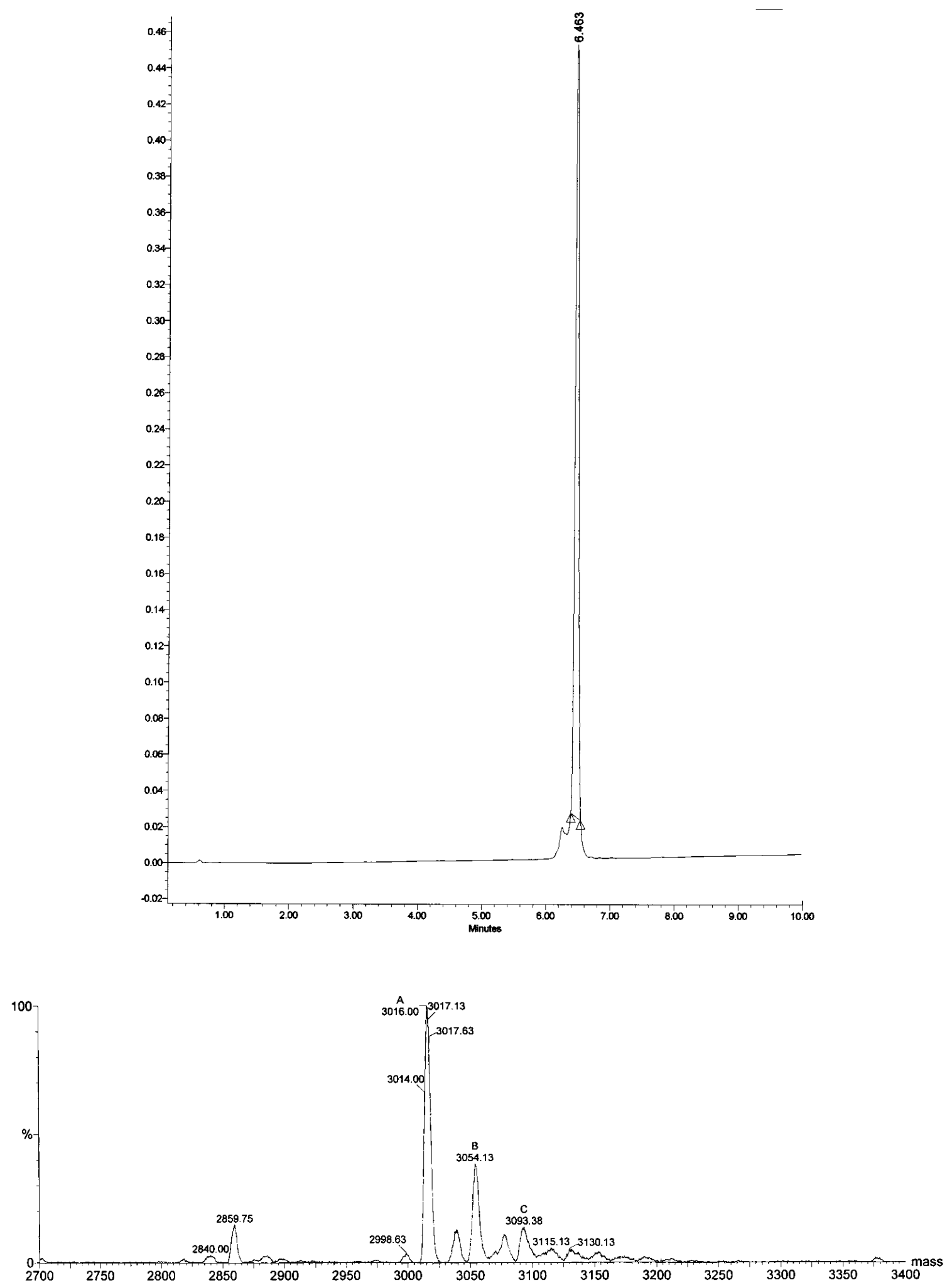


\section{Dendrimer CF}

$0.1 \mathrm{mg}, 10 \%$, RP-HPLC: $t_{\mathrm{R}}=6.47 \mathrm{MS}$ (ES+): calc. for $\mathrm{C}_{126} \mathrm{H}_{146} \mathrm{~N}_{40} \mathrm{O}_{44} \mathrm{~S}_{2}: 2987.00$, found: 2987.88 .
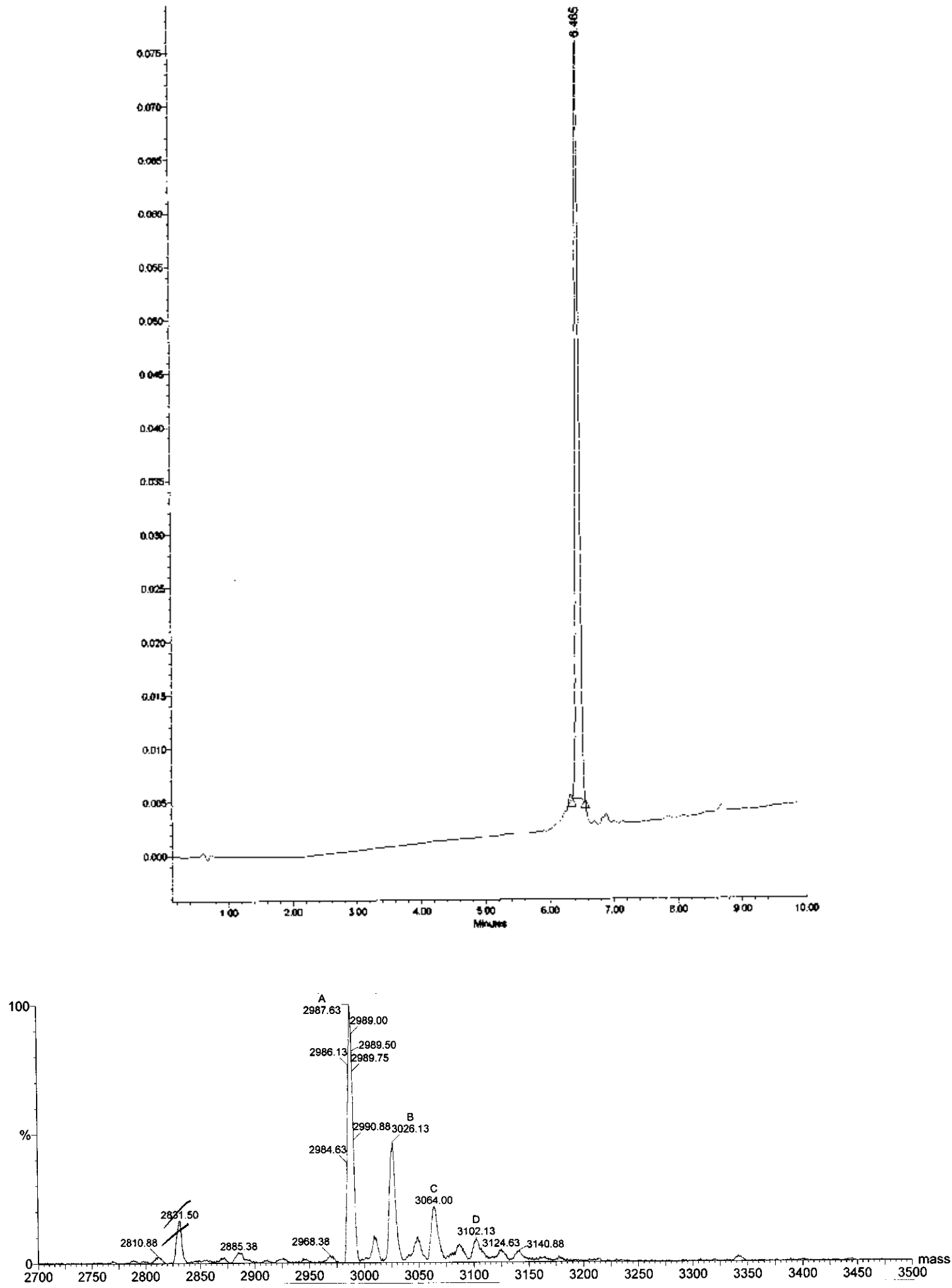


\section{Dendrimer DD}

$0.6 \mathrm{mg}, 60 \%$, RP-HPLC: $t_{\mathrm{R}}=5.76 \mathrm{MS}$ (ES+): calc. for $\mathrm{C}_{136} \mathrm{H}_{142} \mathrm{~N}_{38} \mathrm{O}_{48} \mathrm{~S}_{2}: 3020.96$, found: 3022.25 .
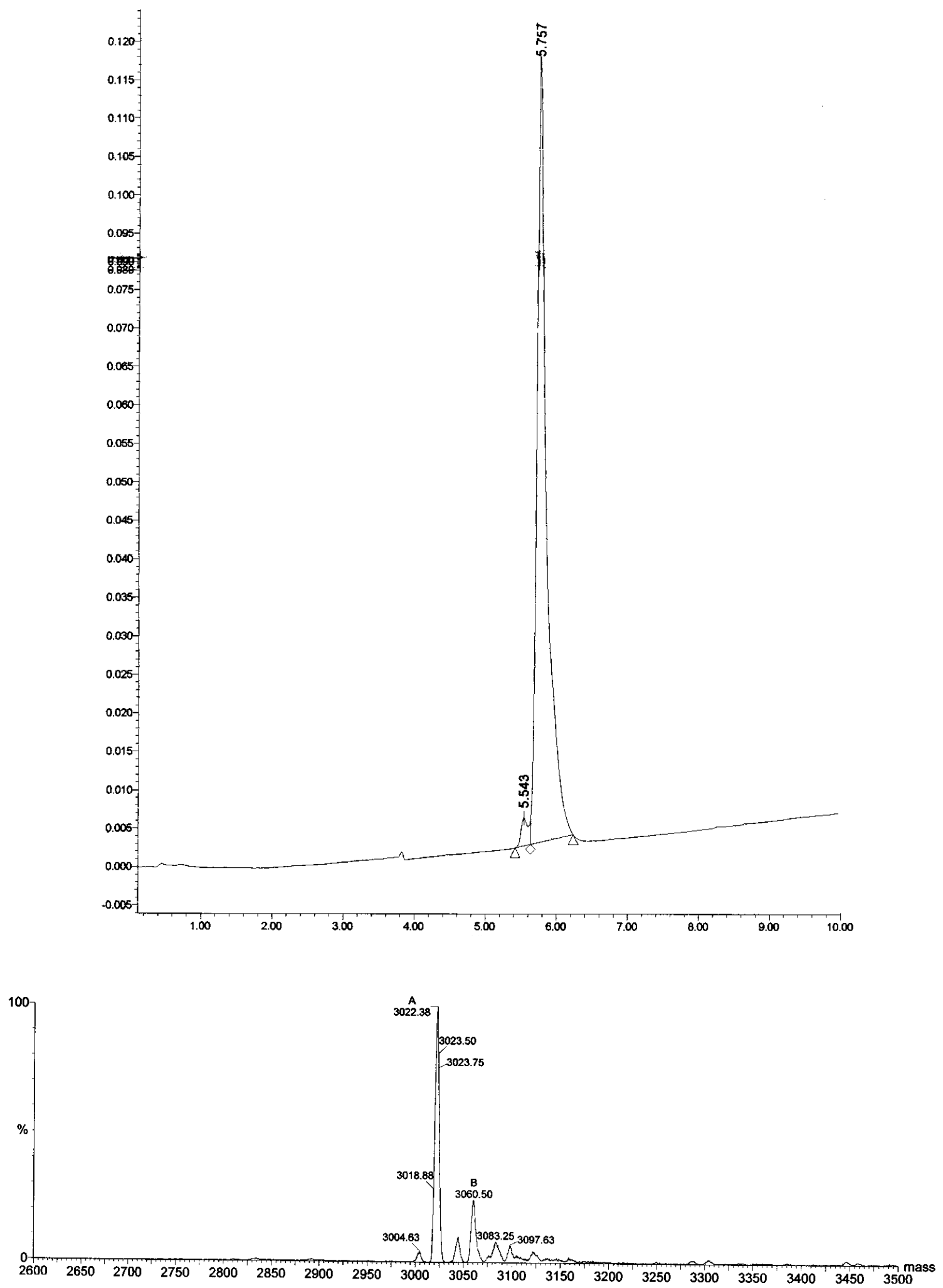


\section{Dendrimer DE}

$0.3 \mathrm{mg}, 30 \%$, RP-HPLC: $t_{\mathrm{R}}=6.08 \mathrm{MS}$ (ES+): calc. for $\mathrm{C}_{130} \mathrm{H}_{148} \mathrm{~N}_{42} \mathrm{O}_{44} \mathrm{~S}_{2}: 3065.02$, found: 3066.25 .
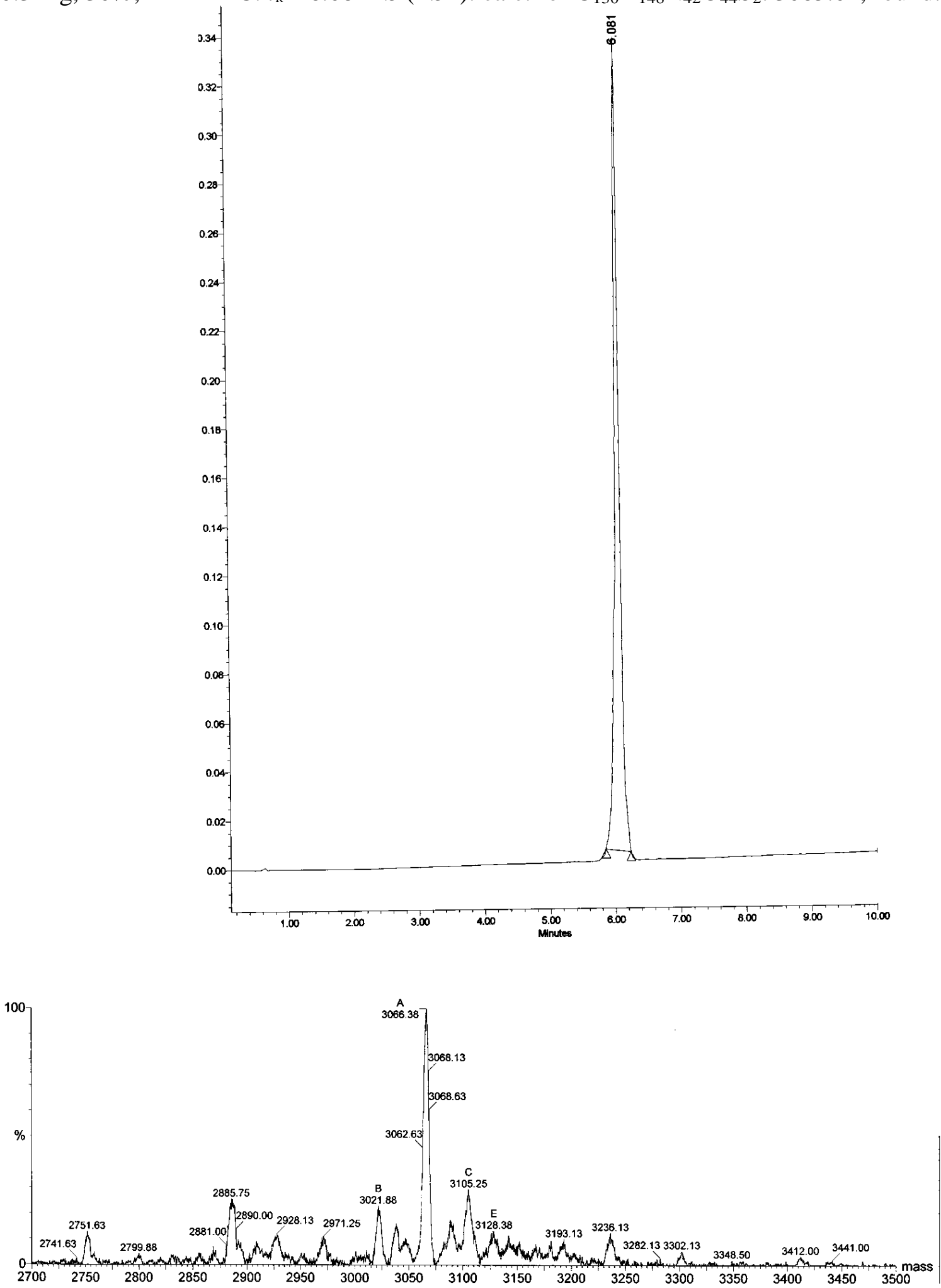


\section{Dendrimer DF}

$0.7 \mathrm{mg}, 35 \%$, RP-HPLC: $t_{\mathrm{R}}=5.88 \mathrm{MS}$ (ES+): calc. for $\mathrm{C}_{129} \mathrm{H}_{148} \mathrm{~N}_{42} \mathrm{O}_{43} \mathrm{~S}_{2}: 3037.03$, found: 3038.63.
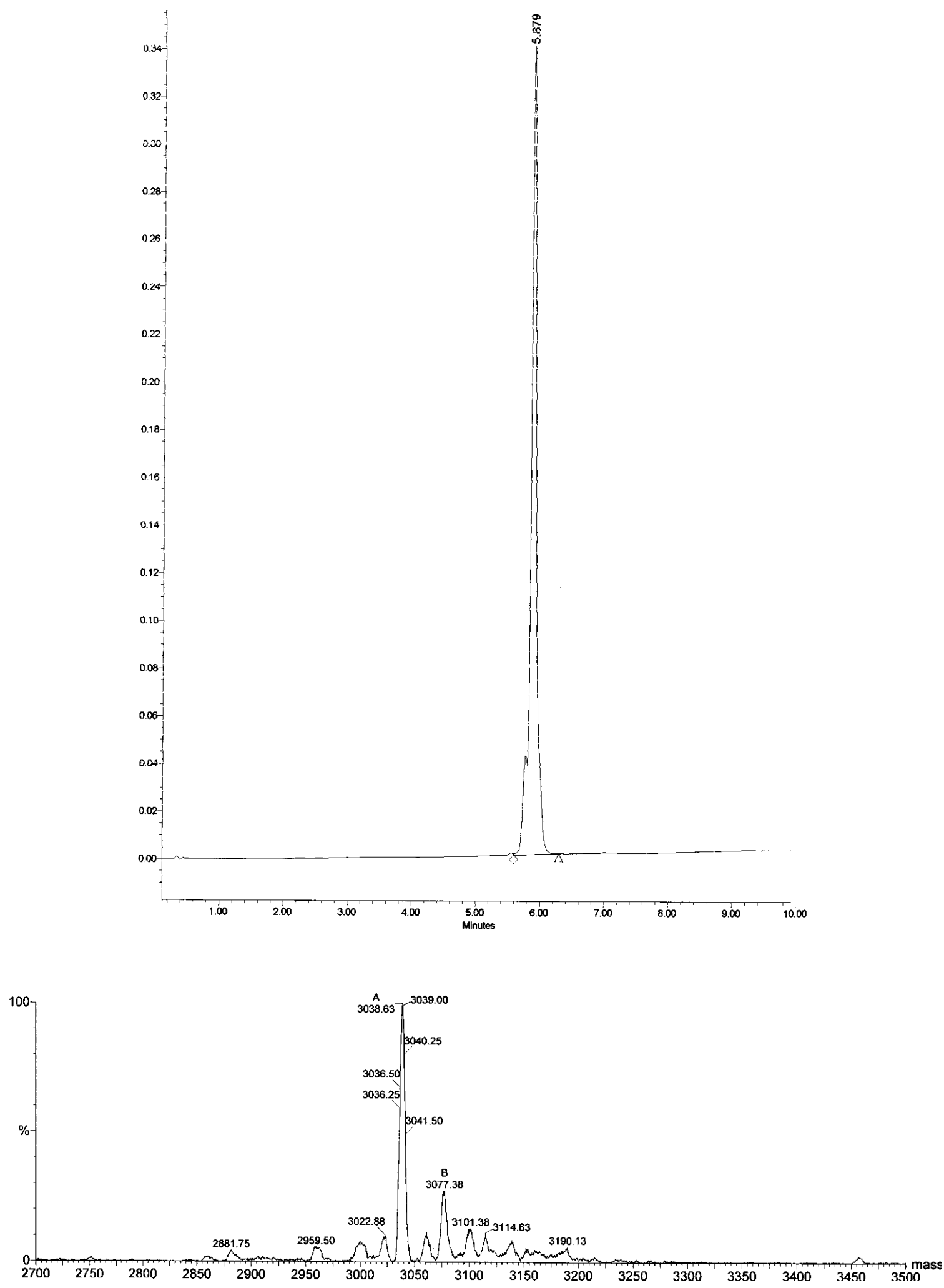


\section{Dendrimer EE}

$0.6 \mathrm{mg}, 60 \%$, RP-HPLC: $t_{\mathrm{R}}=6.13 \mathrm{MS}$ (ES+): calc. for $\mathrm{C}_{134} \mathrm{H}_{150} \mathrm{~N}_{46} \mathrm{O}_{40} \mathrm{~S}_{2}: 3109.08$, found: 3109.88 .
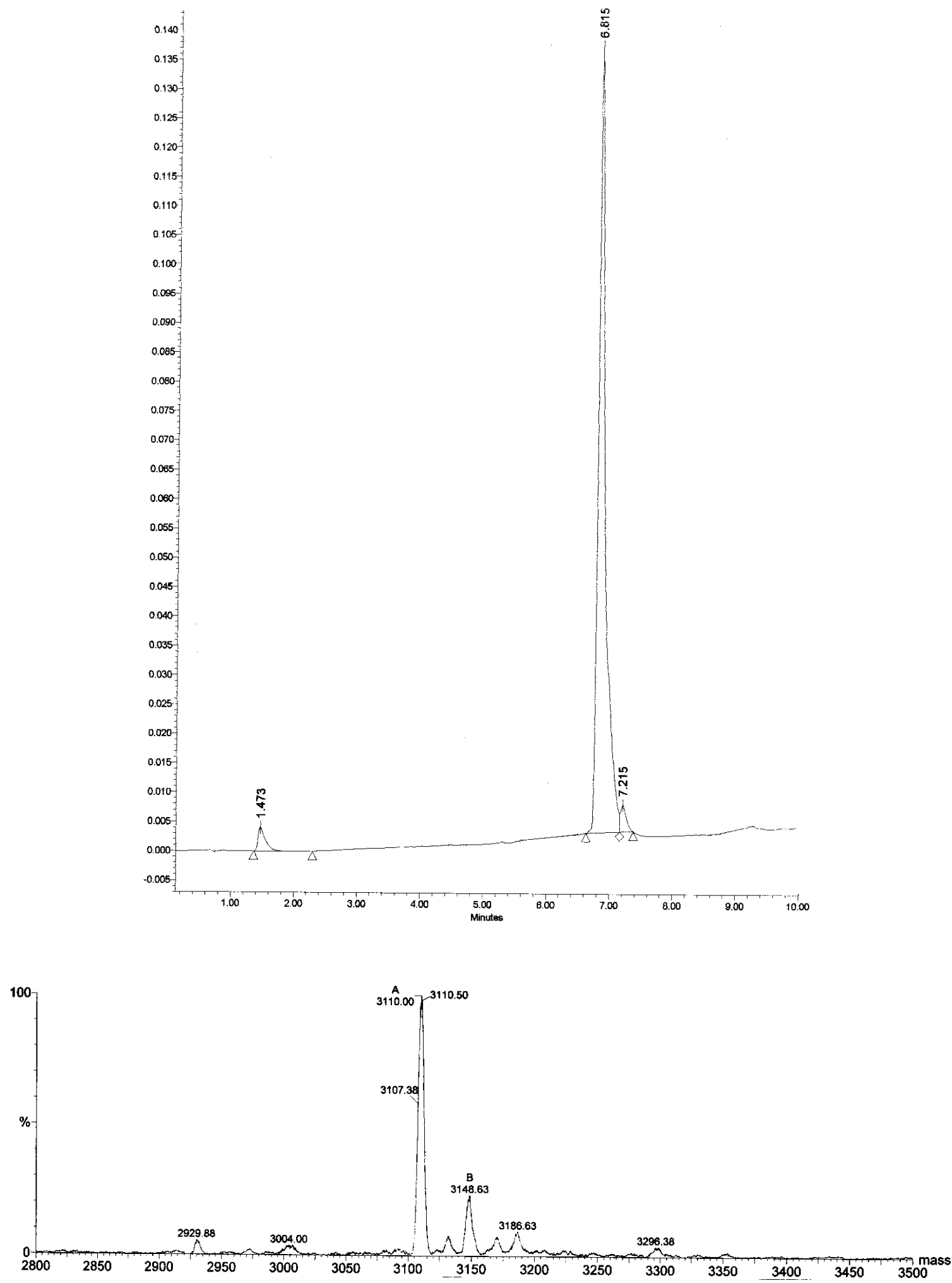


\section{Dendrimer EF}

$0.4 \mathrm{mg}, 40 \%$, RP-HPLC: $t_{\mathrm{R}}=7.04 \mathrm{MS}$ (ES+): calc. for $\mathrm{C}_{133} \mathrm{H}_{152} \mathrm{~N}_{46} \mathrm{O}_{39} \mathrm{~S}_{2}: 3081.09$, found: 3081.88 .
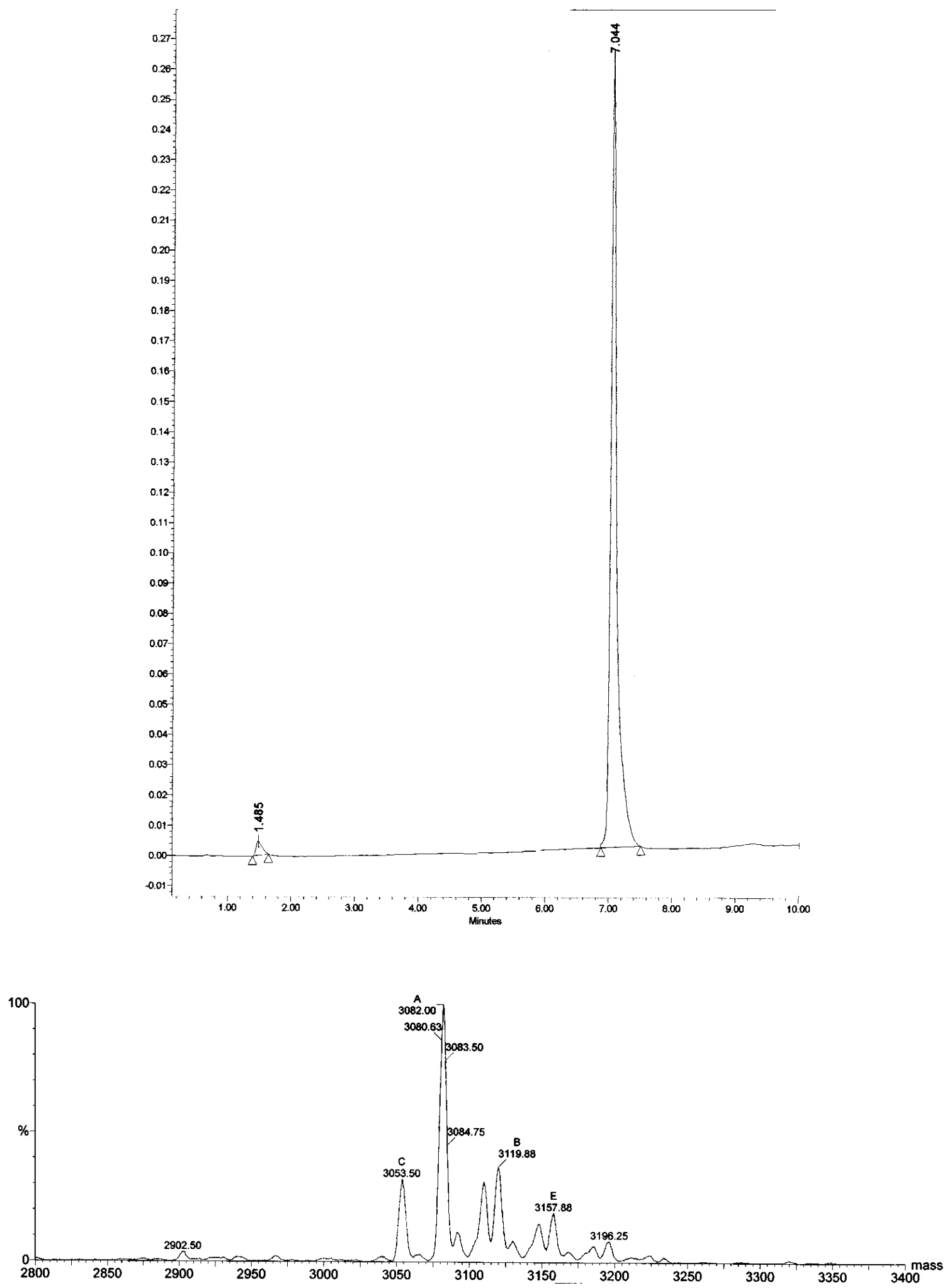


\section{Dendrimer FF}

$0.4 \mathrm{mg}, 40 \%$, RP-HPLC: $t_{\mathrm{R}}=6.16 \mathrm{MS}$ (ES+): calc. for $\mathrm{C}_{134} \mathrm{H}_{150} \mathrm{~N}_{46} \mathrm{O}_{40} \mathrm{~S}_{2}: 3053.10$, found: 3054.25 .
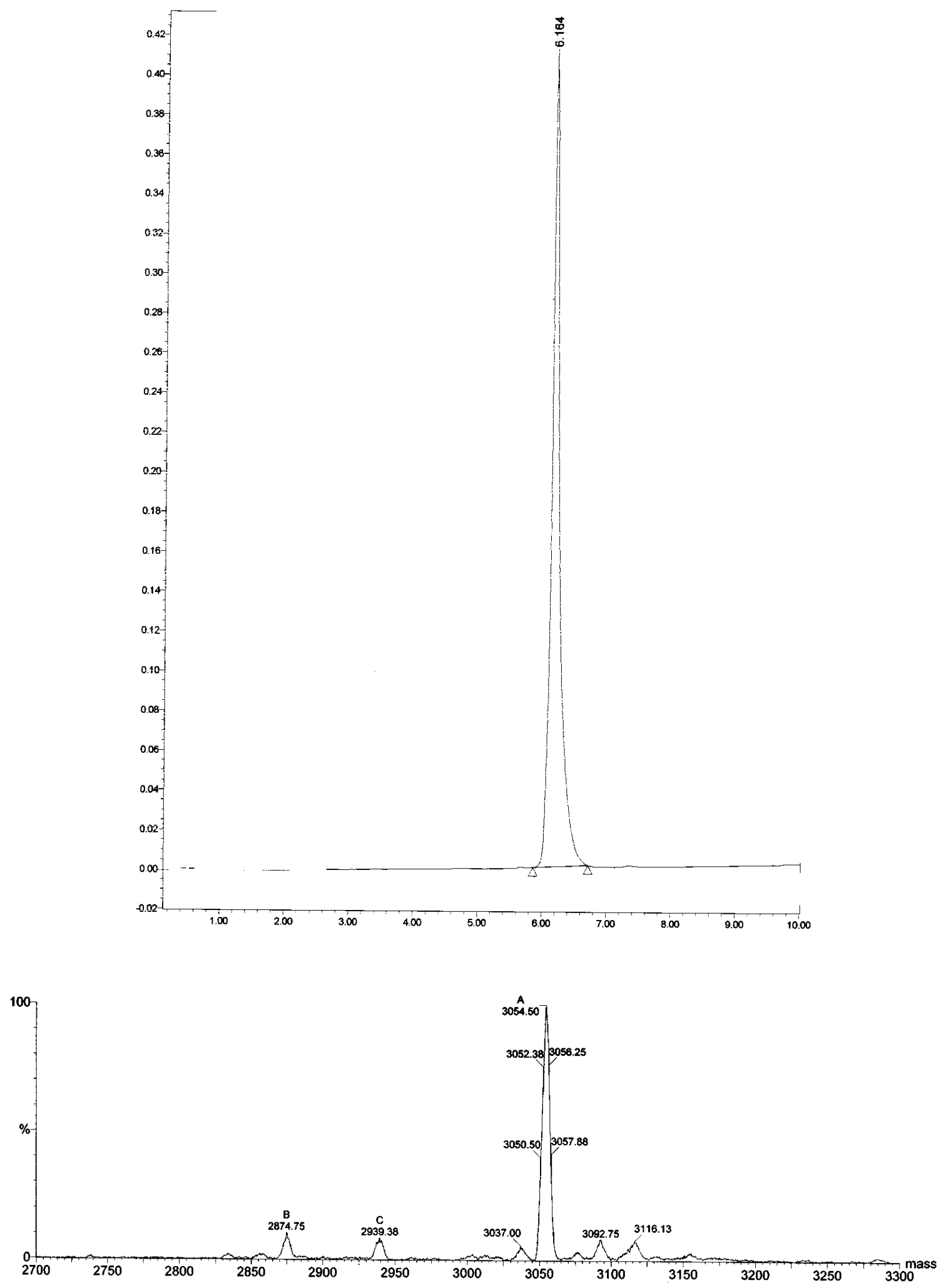


\section{Dendrimer Ala-4}

$0.6 \mathrm{mg}, 60 \%$, RP-HPLC: $t_{\mathrm{R}}=7.85 \mathrm{MS}$ (ES+): calc. for $\mathrm{C}_{114} \mathrm{H}_{136} \mathrm{~N}_{30} \mathrm{O}_{48} \mathrm{~S}_{2}: 2756.88$, found: 2758.38 .
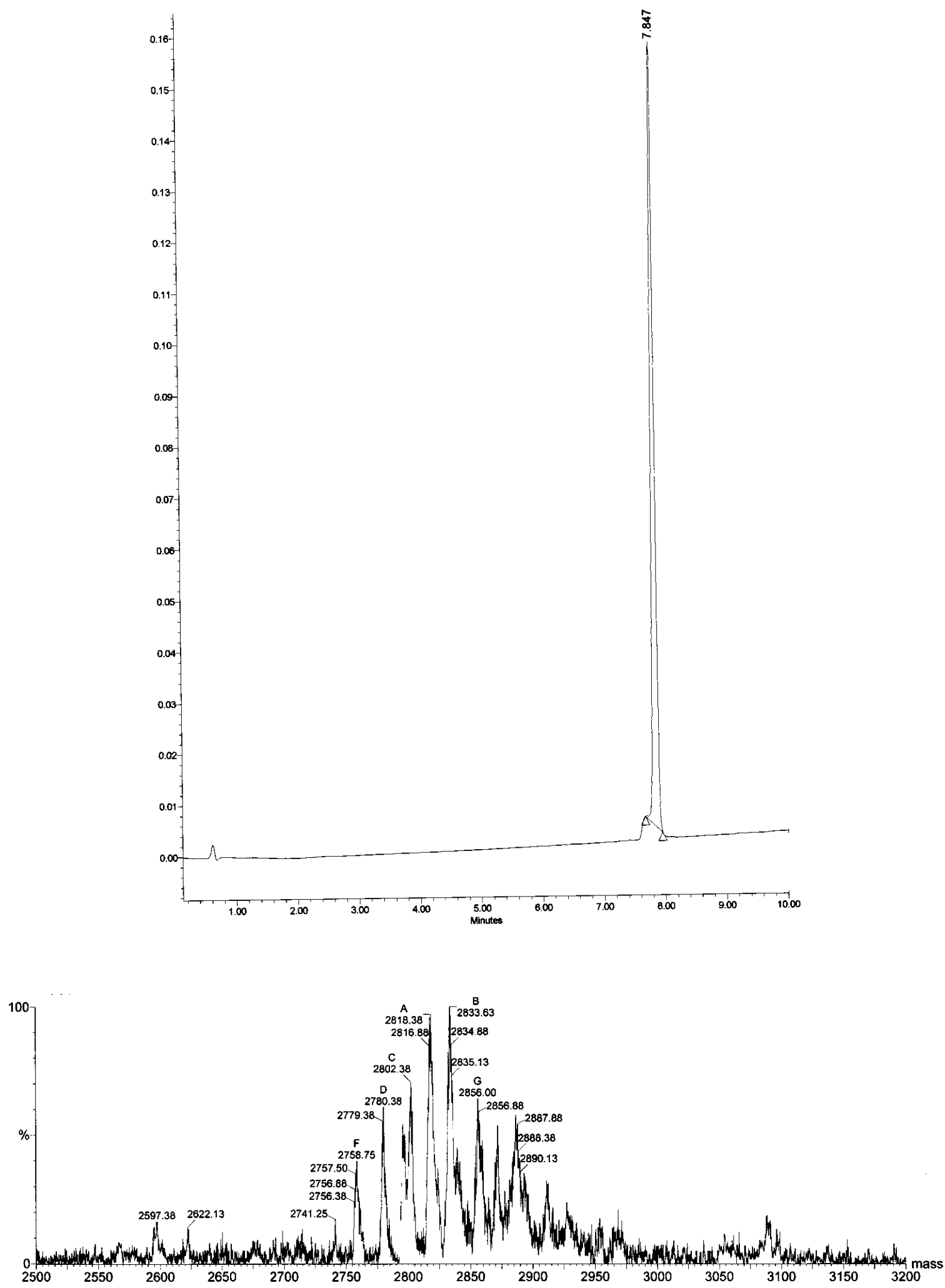


\section{Dendrimer GG}

$0.5 \mathrm{mg}, 50 \%$, RP-HPLC: $t_{\mathrm{R}}=6.24 \mathrm{MS}$ (ES+): calc. for $\mathrm{C}_{126} \mathrm{H}_{144} \mathrm{~N}_{38} \mathrm{O}_{46} \mathrm{~S}_{2}: 2988.96$, found: 2989.88 .
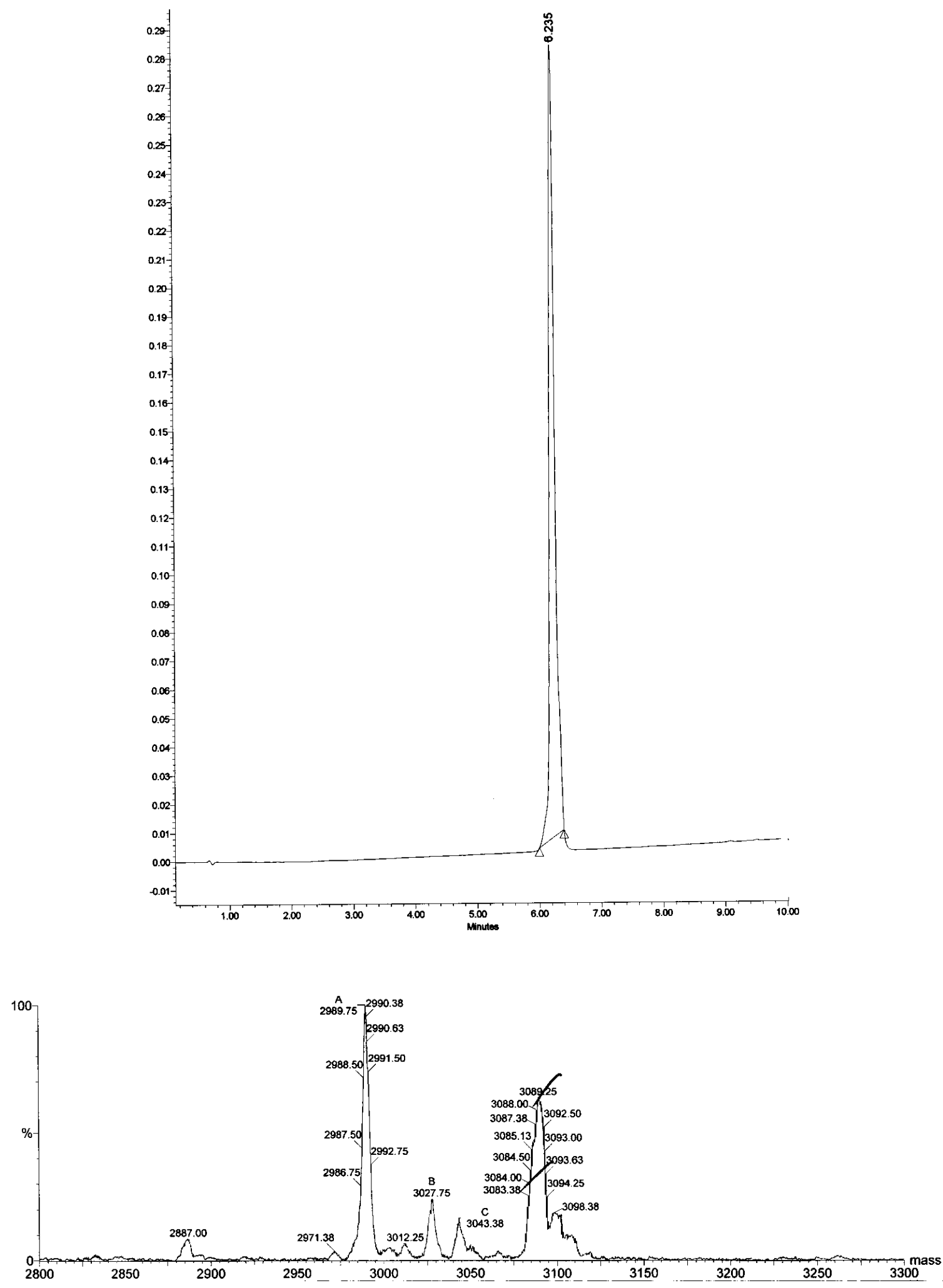


\section{Dendrimer Ala-2'}
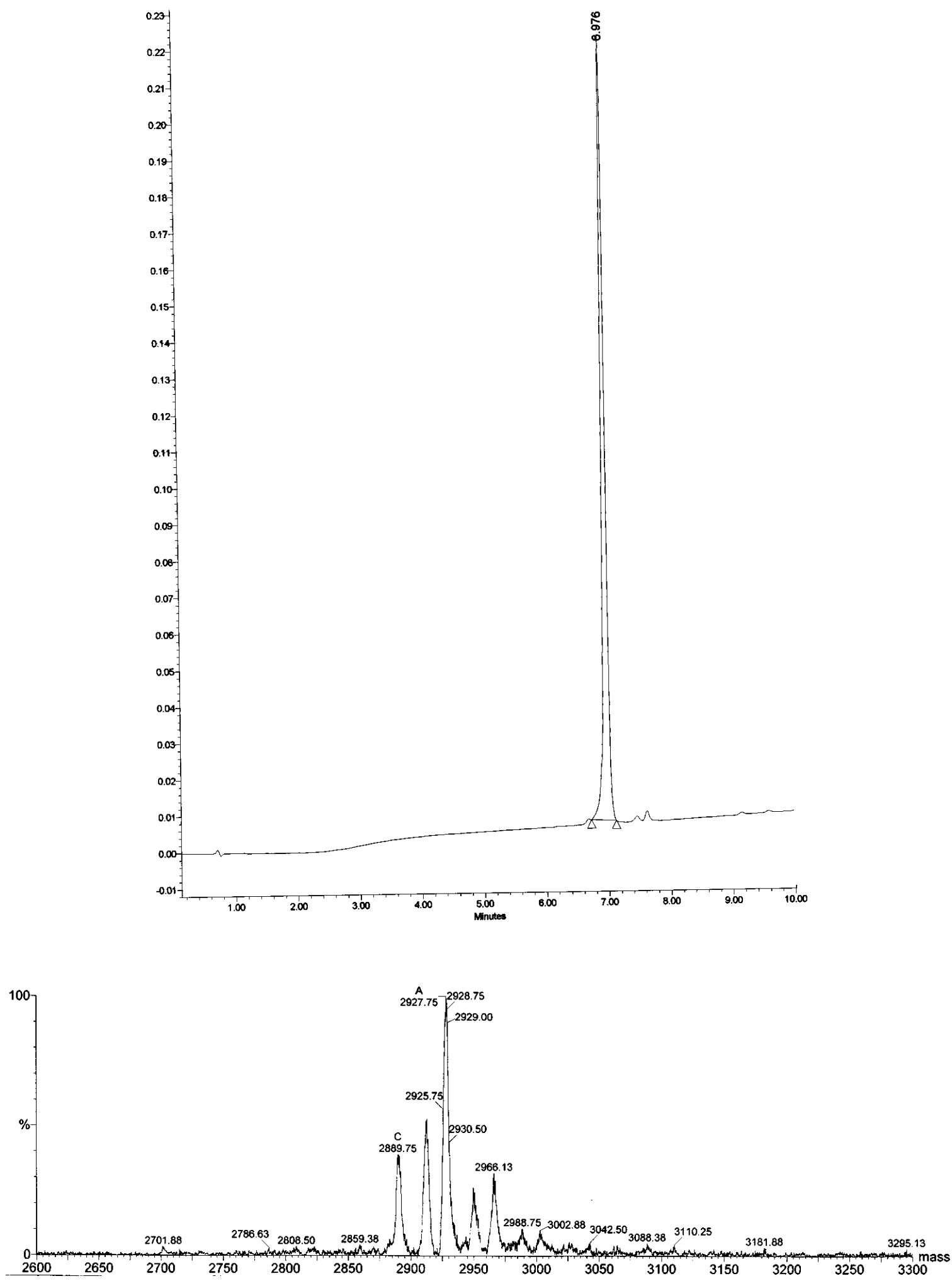


\section{Dendrimer Ala-2}

$0.2 \mathrm{mg}, 19 \%$, RP-HPLC: $t_{\mathrm{R}}=3.13$ (A/B (80:20) to A/B (65:35) in $5 \mathrm{~min}$ ) MS (ES+): calc. for $\mathrm{C}_{120} \mathrm{H}_{140} \mathrm{~N}_{34} \mathrm{O}_{48} \mathrm{~S}_{2}: 2888.92$, found: 2889.00 .
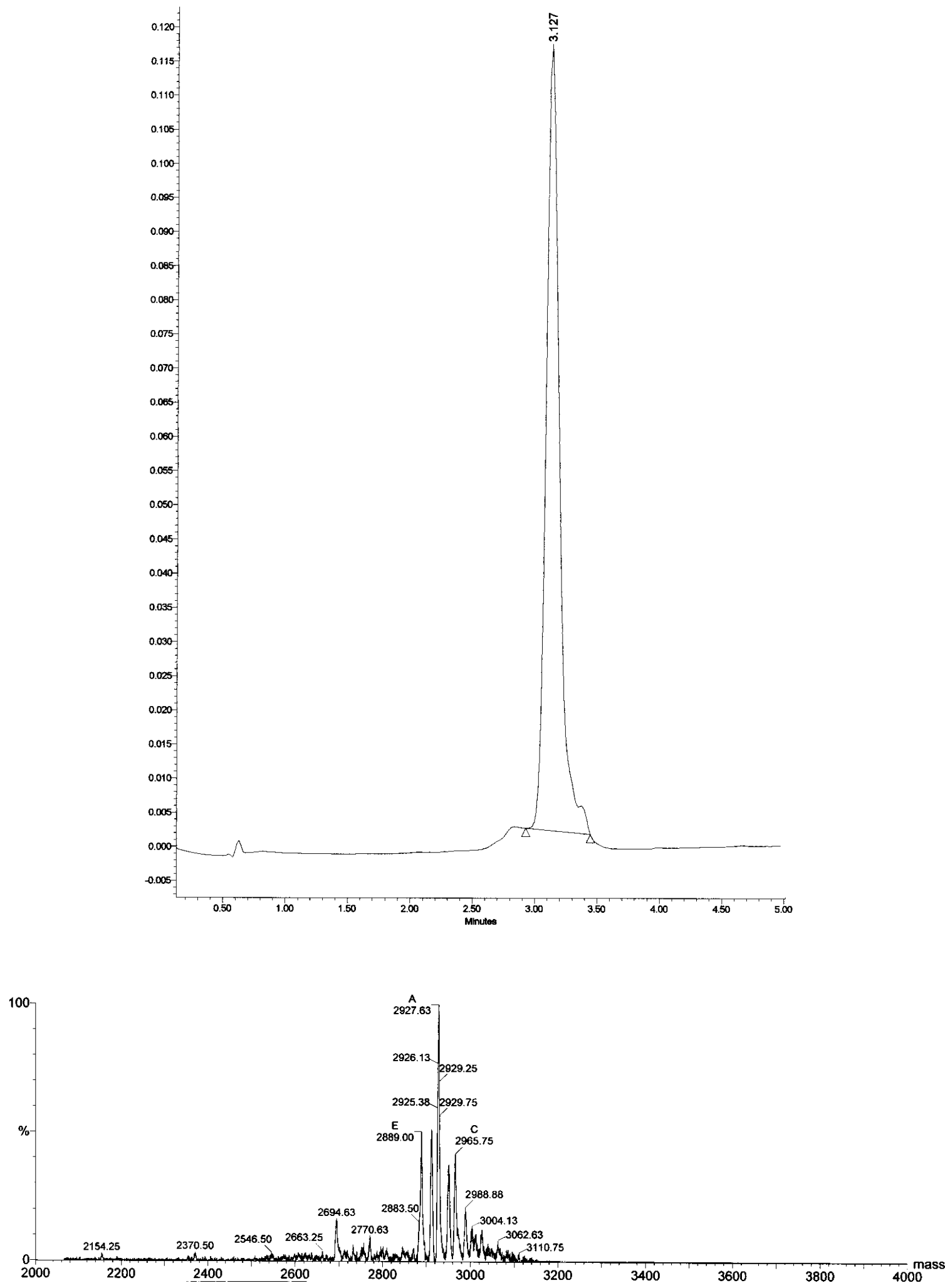


\section{Dendrimer DG}

$0.2 \mathrm{mg}, 36 \%$, RP-HPLC: $t_{\mathrm{R}}=6.27 \mathrm{MS}$ (ES+): calc. for $\mathrm{C}_{126} \mathrm{H}_{144} \mathrm{~N}_{38} \mathrm{O}_{47} \mathrm{~S}_{2}: 3004.96$, found: 3005.88 .
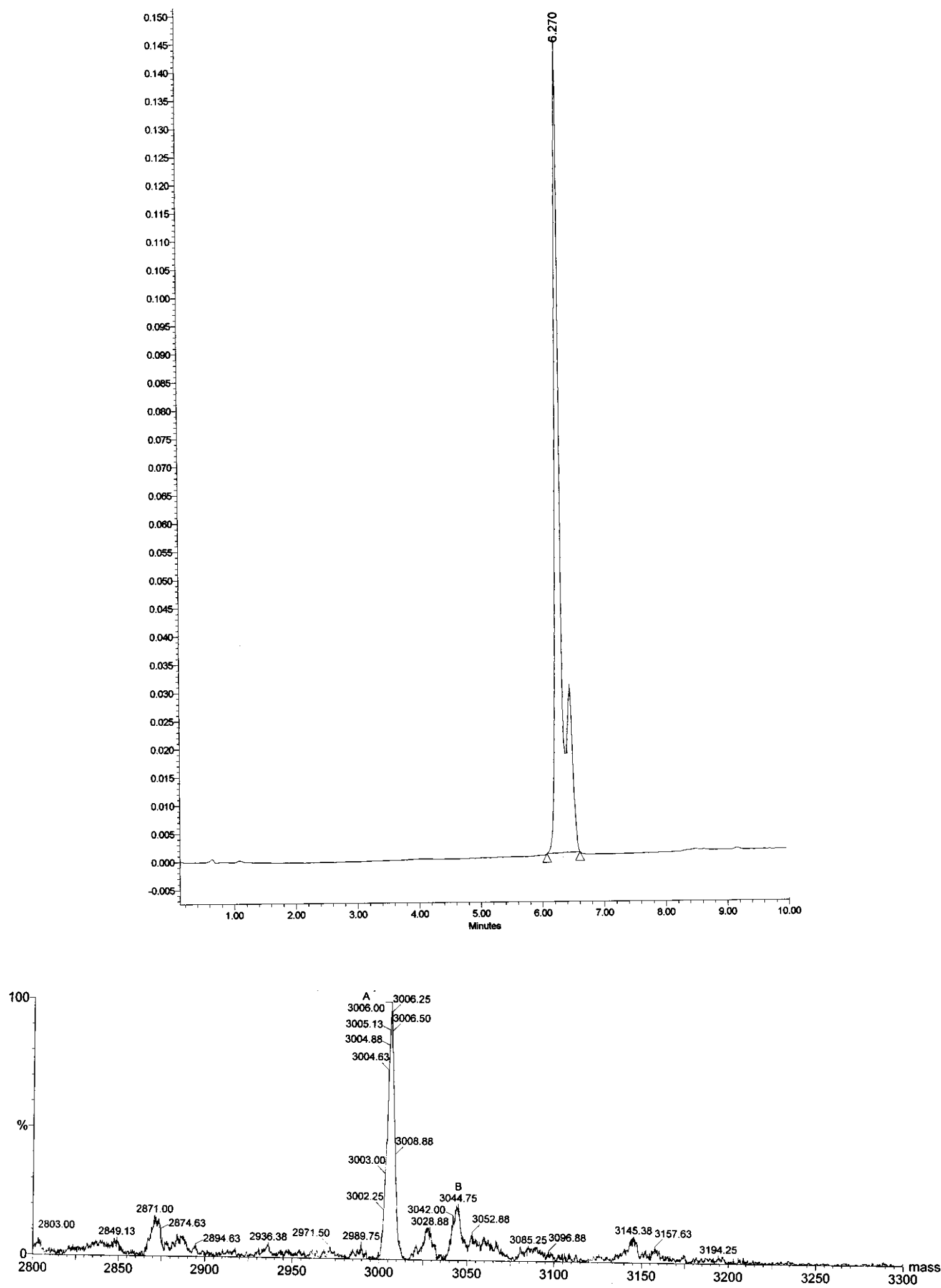


\section{Dendrimer Ala-1}

$0.2 \mathrm{mg}, 14 \%$, RP-HPLC: $t_{\mathrm{R}}=2.01$ (A/B (80:20) to A/B (50:50) in $10 \mathrm{~min}$ ) MS (ES+): calc. for $\mathrm{C}_{123} \mathrm{H}_{142} \mathrm{~N}_{36} \mathrm{O}_{48} \mathrm{~S}_{2}: 2954.94$, found: 2955.75 .
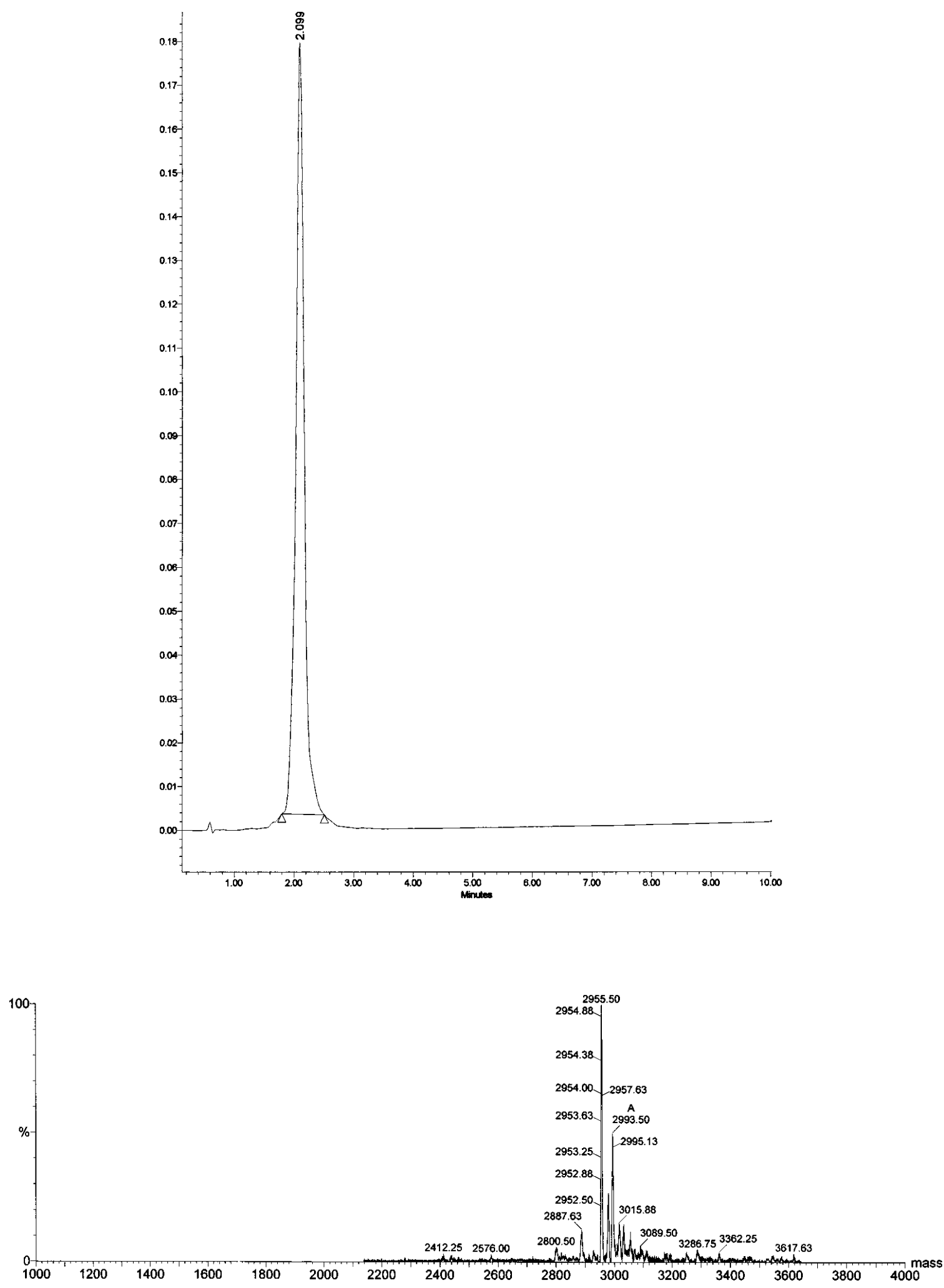


\section{Dendrimer Ala-3}

$0.1 \mathrm{mg}, 10 \%$, RP-HPLC: $t_{\mathrm{R}}=3.84$ (A/B (80:20) to A/B (50:50) in $\left.10 \mathrm{~min}\right) \mathrm{MS}(\mathrm{ES}+)$ : calc. for $\mathrm{C}_{117} \mathrm{H}_{138} \mathrm{~N}_{32} \mathrm{O}_{48} \mathrm{~S}_{2}: 2822.9$, found: 2823.63 .
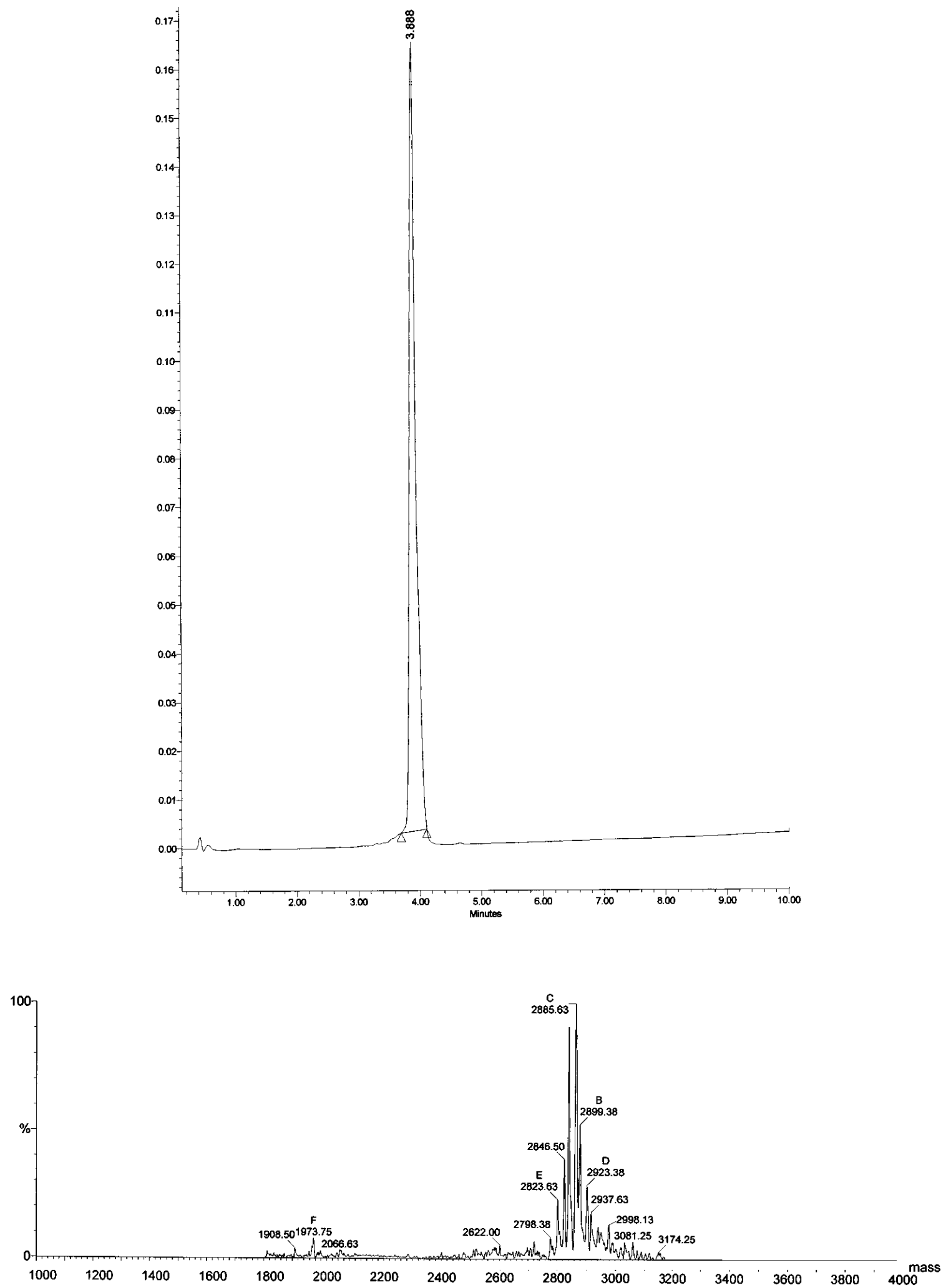


\section{Dendrimer JJ}

$0.5 \mathrm{mg}, 50 \%$, RP-HPLC: $t_{\mathrm{R}}=7.17 \mathrm{MS}$ (ES+): calc. for $\mathrm{C}_{130} \mathrm{H}_{152} \mathrm{~N}_{46} \mathrm{O}_{30} \mathrm{~S}_{2}: 2901.14$, found: 2902.50 .
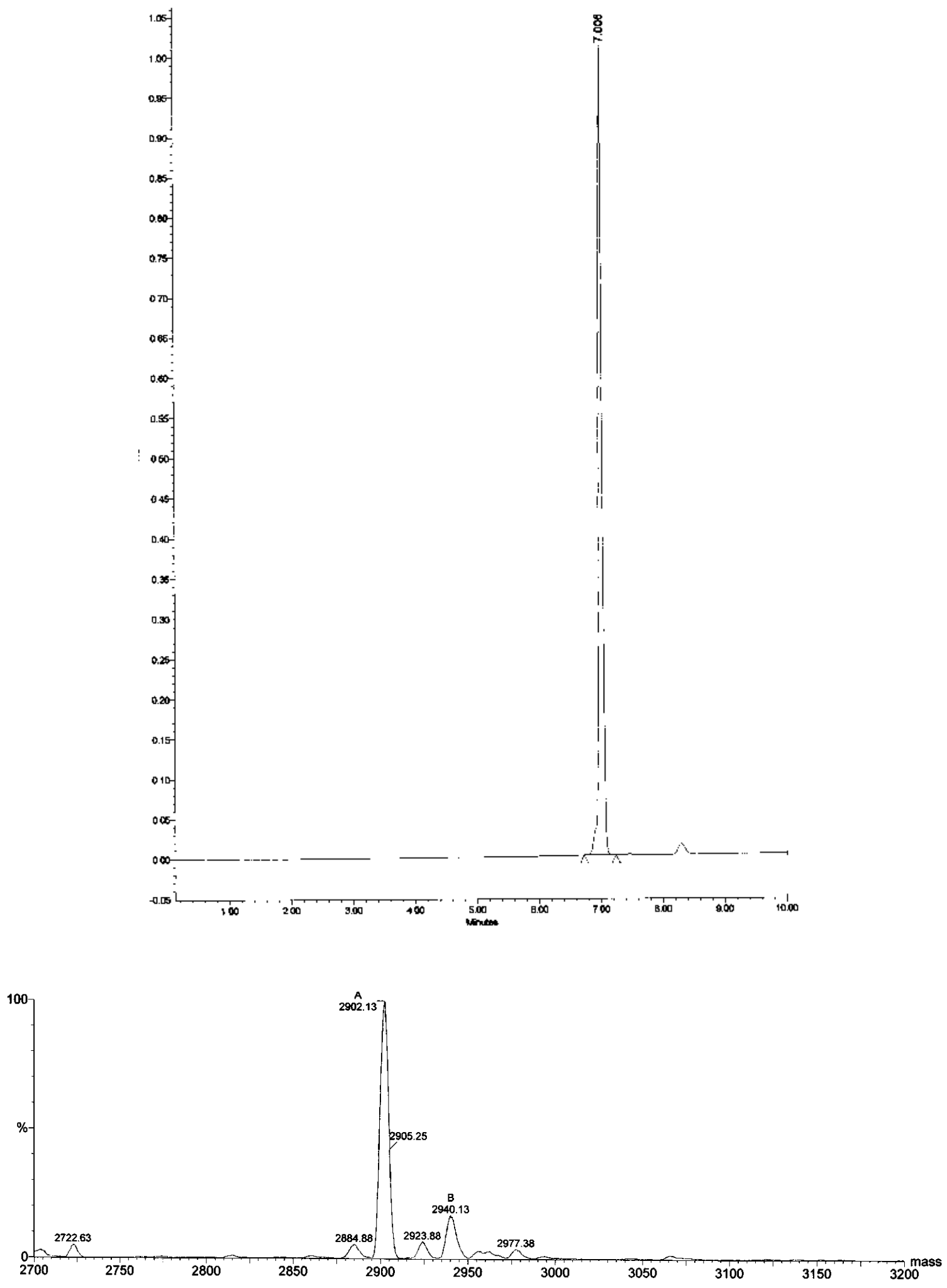